\title{
Bioinspired nanochannels based on polymeric membranes
}

\author{
$\mathrm{He} \mathrm{Ma}{ }^{1}$, Song Wang ${ }^{1}$, Bing $\mathrm{Yu}^{1,2}$, Xin Sui ${ }^{1 *}$, Youqing Shen ${ }^{1,3}$ and Hailin Cong ${ }^{1,2^{*}}$
}

\begin{abstract}
Bio-nanochannels in living organisms participate in the physiological activities by selectively transporting ions through cell membranes. The structure and function of biological ion channels inspire the development of artificial ion nanochannels with practical applications. The bioinspired nanochannels based on polymer materials present good mechanical stability, high-performance ion transport and designability, which have attracted much attention. In this review, we mainly focus on the fabrication and application of polymer-based biomimetic nanochannels especially in environmentally responsive biosensor and energy conversion. We firstly introduce the basic understanding of nanochannels in ion regulation and osmotic energy conversion. Then, we discuss the fabrication methods of polymer-based nanochannels and highlight their advantages compared with other materials. The practical applications of polymer-based biomimetic nanochannels, especially in energy conversion and environmentally responsive biosensor, are detailedly discussed. Finally, we summarize the unsolved problems in bioinspired nanochannels and overview the further developing direction in this field.
\end{abstract}

Keywords: bioinspired nanochannel, polymeric membrane, environmentally responsive biosensor, energy conversion

\section{INTRODUCTION}

In organisms, biological nanochannels regulate the ion transport across cell membranes to achieve complex life activities, such as maintaining cell ion homeostasis, signal transduction, and energy generation [1]. For example, electric eels can utilize ion channels in the plasma membrane [2] to convert the salinity gradient energy into bioelectricity [3], generating an action potential of up to
$600 \mathrm{~V}$ for hunting or self-defense [4]. These biological nanochannels seem to be powerful assistants in many fields [5], such as molecular separation, biosensing and energy conversion. However, the lipid bilayer is fragile and sensitive, and it is difficult to artificially adjust working environment to biological systems. Inspired by biological nanochannels, researchers have developed artificial nanochannels functioning like the ion channel or nanopore in biological system membranes [1,6,7], called "bioinspired nanochannels" [8-12]. Bioinspired nanochannels have significant advantages over nanochannels embedded in lipid membranes: chemical and physical stability, flexibility in size and shape, and easy fabrication of high-density arrays $[13,14]$.

The materials of biomimetic nanochannel are mainly divided into biological materials, inorganic materials, organic and composite materials $[14,15]$. The application of biological materials is limited due to their low strength and harsh requirements for external working conditions [16]. Inorganic materials, which have the advantages of high strength, stable structure and physicochemical properties, play an important role in the construction of nanochannels [17-19]. For example, anodic alumina membrane (AAO) has a pore density up to $10^{9} \mathrm{~cm}^{-2}$, and its shape and size are relatively controllable. In addition, the exposed hydroxyl groups on the inner surface of the channel can be used to further modify functional groups to achieve more complex functions [20]. Zhang et al. [21] introduced the redox-active polypyrrole into the channel of AAO to form an intelligent unipolar nanofluid diode. Zhang et al. [22] explored the effect of the length of functional molecules on gating performance with symmetric AAO channels. In addition, two-dimensional (2D)

\footnotetext{
${ }^{1}$ Institute of Biomedical Materials and Engineering, College of Materials Science and Engineering, College of Chemistry and Chemical Engineering, Affiliated Hospital of Qingdao University, Qingdao University, Qingdao 266071, China

${ }^{2}$ State Key Laboratory of Bio-Fibers and Eco-Textiles, Qingdao University, Qingdao 266071, China

${ }^{3}$ Key Laboratory of Biomass Chemical Engineering of Ministry of Education, Center for Bionanoengineering, Department of Chemical and Biological Engineering, Zhejiang University, Hangzhou 310027, China

* Corresponding authors (emails: hailincong@yahoo.com (Cong H); suixin_1991@126.com (Sui X))
} 
inorganic materials are also widely concerned because of their unique layered structures. For example, carbonitride, as an excellent semiconductor and photocatalyst material, has strong light absorption. Efficient photoelectric conversion can be realized by the layered structure designed from carbon nitride [23,24]. Organic materials can be used to prepare nanochannels of different shapes by using an etching process, and then different functional groups can be grafted on the channels to achieve different functions, such as responding to external stimuli and energy conversion [25-27]. Composite materials based on the combination of biological, inorganic and organic materials $[28,29]$ achieve multifunctional nanochannels, combining the advantages of different materials [30,31]. For example, Chen et al. [32] modified the AAO nanochannels with the cyclic 3',5'adenosine monophosphate (cAMP) response molecule. The biomimetic nanochannel with high controllability and excellent reversibility provides a great potential in the application of nanofluidic devices. The superb intelligent behavior of ion channels in organisms originates from the symmetric or asymmetric structure and chemical composition. The interface characteristics of the bioinspired nanochannels between the electrolyte solution and the inner surface of channels strongly depend on the surface adjustment of the nanochannels containing symmetric and asymmetric chemical modification, particularly in the application of biosensors [33]. Different techniques including chemical electroless deposition [34], solution chemical reaction [35,36], self-assembly modification [37], ion sputtering [38], electron beam evaporation [39] and plasma [40] are usually utilized for modification.

Bioinspired polymer nanochannels with excellent properties and designability have attracted much attention. Polymeric nanochannel membrane is advantageous over other materials in many aspects: (1) polymer membranes can solve the mechanical problems of inorganic films and limited variety of inorganic materials [41]; (2) the track-etched technology for polymer nanochannel is a feasible way for artificial nanochannel fabrication for many advantages such as a defined size and geometry [42]; (3) the inner surface of polymer nanochannels exposes active chemical groups under specific condition, enabling further functionalization [43-45]; (4) the stable polymer membrane overcomes the mechanical problems of lipid bimolecular membrane, and the polymer membrane can withstand higher transmembrane potential, which can theoretically improve the accuracy of chemical detection $[13,14,46]$. Herein, we systematically demonstrate the development of bioinspired nanochannels based on polymer membranes, and mainly discuss the construction methods and practical applications (Fig. 1). This review consists of four sections: first, we briefly introduce the bioinspired nanochannels and their basic properties; then, we overview the construction methods of the polymer-based systems including homopolymer membrane and block copolymer (BCP) membrane. The third section summarizes the applications of the polymer membranes, including biochemical sensing and energy conversion. This section introduces the nanochannels with environmental responses, such as $\mathrm{pH}$ response, photo-response, temperature-response, ion-response and multi-response. The applications in energy conversion mainly include photoelectric conversion and osmotic energy conversion. Finally, we outlook the future development of the polymer-based systems.

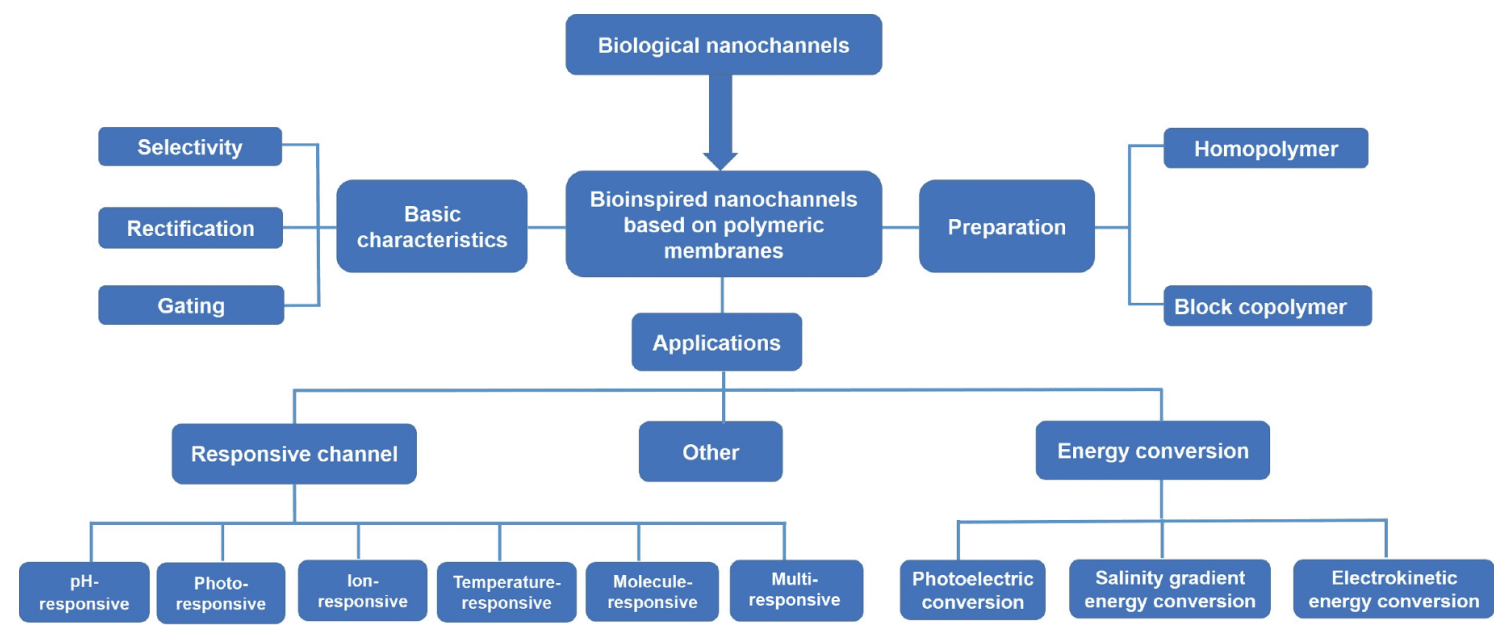

Figure 1 Diagram of the strategy to construct the polymer-based bioinspired nanochannel membranes. 


\section{BASIC CHARACTERISTICS OF NANOCHANNELS}

Biological ion channels constructed by membrane proteins can get open and closed in response to external stimuli to regulate ion transport across the cell membrane $[9,47]$, which is an important physiological activity in the metabolism of living cells. Like biological ion channels, bioinspired nanochannels also have three basic characteristics associated with wide biological roles: ion selectivity, ion gating and ionic rectification [14]. The interaction between the transmembrane ions and the charges on the inner surface of the channel is the main reason why ion transport can be regulated. Ion selectivity is a main functional property of biological ion channels, which can precisely control the transportation of ions. Biological ion channels usually select ions of different sizes to enter and exit the cell membranes by volume exclusion. However, bionic nanochannels mainly use electrostatic effects to distinguish ions $[48,49]$. The electrochemical property of nanochannels is determined by the electric double layer (EDL) when ions transport through suitable size nanochannels. Fig. 2 shows that when the size of the channel is compressed to the nanometer level, EDL can effectively control the ion transmission, which endows the system with ion selective property $[50,51]$. When the length of Debye shielding $\left(\lambda_{\mathrm{D}}\right)$ is similar to the size of channel cross-section in dilute electrolytes [48], the surface charge would control the transmission by repelling co-ions and concentrating counterions. It means that these nanochannels are selective for counteracting ions [52].

The ionic rectification of nanochannels usually refers to that ion currents preferentially transmit under bias in one direction and are suppressed under bias in the opposite direction, which is caused by the electrostatic interaction between the ions and the surface charges inside the channel [48]. The rectification effect must meet three conditions [49]: first, structurally asymmetric nanochannels are required [53], and the diameter of the smaller entrance should be commensurate with the length of the Debye layer. Secondly, there should be charges on

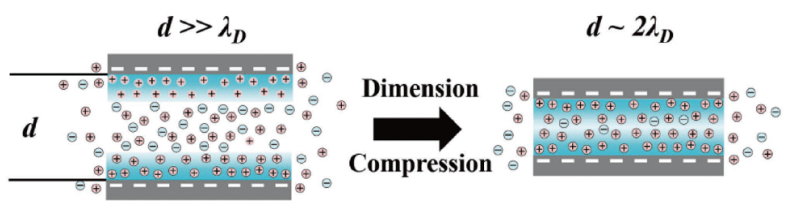

Figure 2 Ion transport in channels with dimensions $d \gg \lambda_{\mathrm{D}}$ and $d \approx$ $2 \lambda_{\mathrm{D}}$. Reprinted with permission from Ref. [51], Copyright 2018, John Wiley and Sons. the inner surface of the channel. Finally, the interaction between the ions and charges in the channel wall should be asymmetric at the two ends of the channel [54]. The open and closed properties of biomimetic nanochannels to various external stimuli are called ionic gating $[49,55]$. The ionic gating characteristic is mainly controlled by the properties of the inner surface of the channel, including clogging [37], surface charge distribution [56,57], wettability and geometry $[58,59]$. Of course, for some specific nanochannels, ionic gating may be affected by multiple factors simultaneously.

At present, the design and preparation processes of bioinspired nanochannels are usually implemented through two schemes. One is to utilize the characteristics of certain materials, such as the responsiveness to specific external conditions. If these materials can be directly used to fabricate nanochannels, the nanochannels will inherit the similar characteristics. The other is to functionalize some nanochannels [14]. We can use functional molecules to achieve the control of various stimulating ion migrations in the nanochannels $[9,56,60,61]$. In next section, we will briefly introduce the preparation processes of polymer-based nanochannels.

\section{PREPARATION OF BIOINSPIRED NANOCHANNELS BASED ON POLYMER}

\section{Homopolymer nanochannels}

Polymer-based nanochannels are the most available and functionalized substrates in solid nanochannels. Track etching technology is the most commonly used method for the preparation of polymer-based nanochannels for two main reasons: nanochannels of various shapes can be prepared by track etching $[9,62]$, such as cylinder $[63,64]$, dumbbell type [65], hourglass type [66-68], cigar type [60], cone type [69], and bullet type [26] (Fig. 3). The other is that activated carboxylic acid groups can be generated on the inner wall of some polymer nanochannels after chemical etching which can be used for some simple amidation or esterification reactions, providing convenience for further functionalization of nanochannels [44]. Firstly, the polymer film is penetrated by high-energy heavy ions to form a pen diameter trace at the scale of several nanometers [70]. Then, selective chemical etching is carried out on the damaged highenergy ion trace area to ensure that other areas are basically unaffected, so as to prepare nanochannels with controllable pore size. The usual preparation process is as follows (Fig. 4) [3,71]. For polyethylene terephthalate (PET) films, $\mathrm{NaOH}$ solution is used as the etching agent 


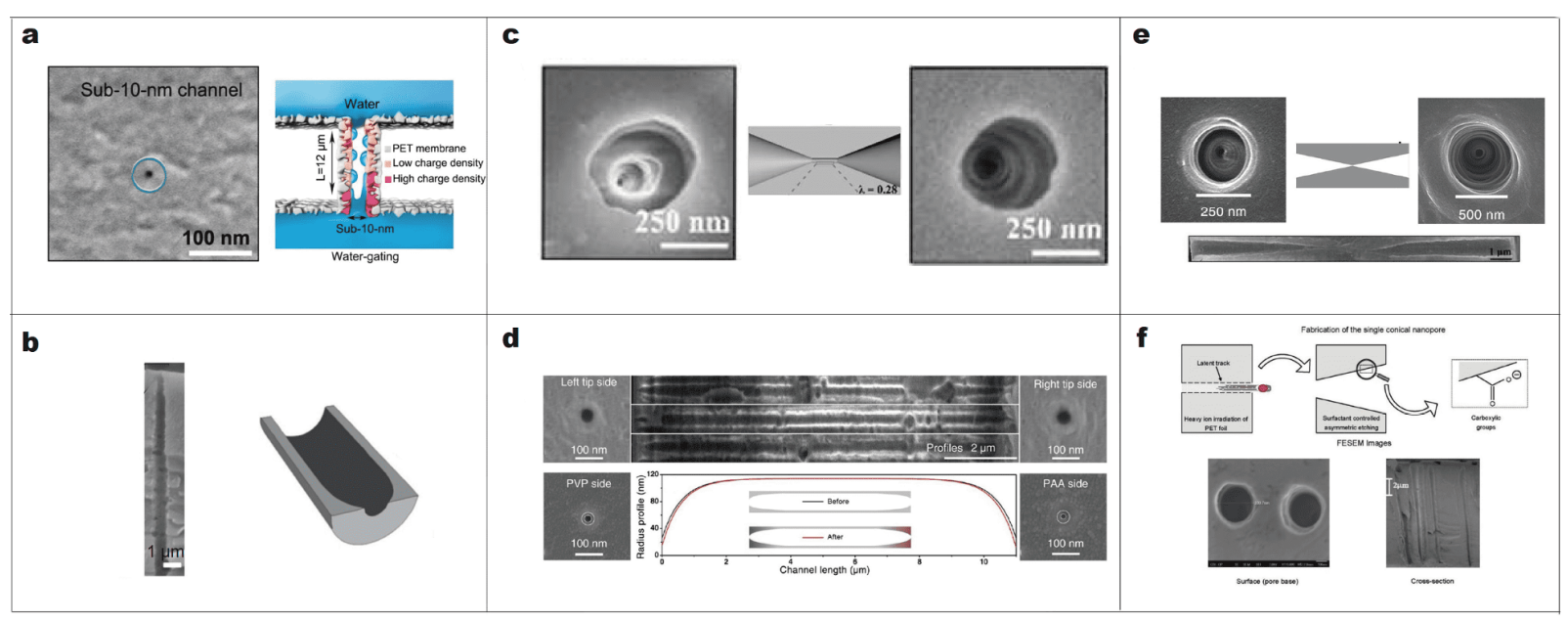

Figure 3 Different shapes of nanochannels. (a) Cylinder. Reprinted with permission from Ref. [64], Copyright 2016, American Chemical Society. (b) Bullet. Reprinted with permission from Ref. [26], Copyright 2017, WILEY-VCH Verlag GmbH \& Co. KGaA, Weinheim. (c) Dumbbell. Reprinted with permission from Ref. [65], Copyright 2018, The Royal Society of Chemistry. (d) Cigar. Reprinted with permission from Ref. [60], Copyright 2013, American Chemical Society. (e) Hourglass. Reprinted with permission from Ref. [67], Copyright 2014, WILEY-VCH Verlag GmbH \& Co. KGaA, Weinheim. (f) Cone. Reprinted with permission from Ref. [69], Copyright 2009, American Chemical Society.
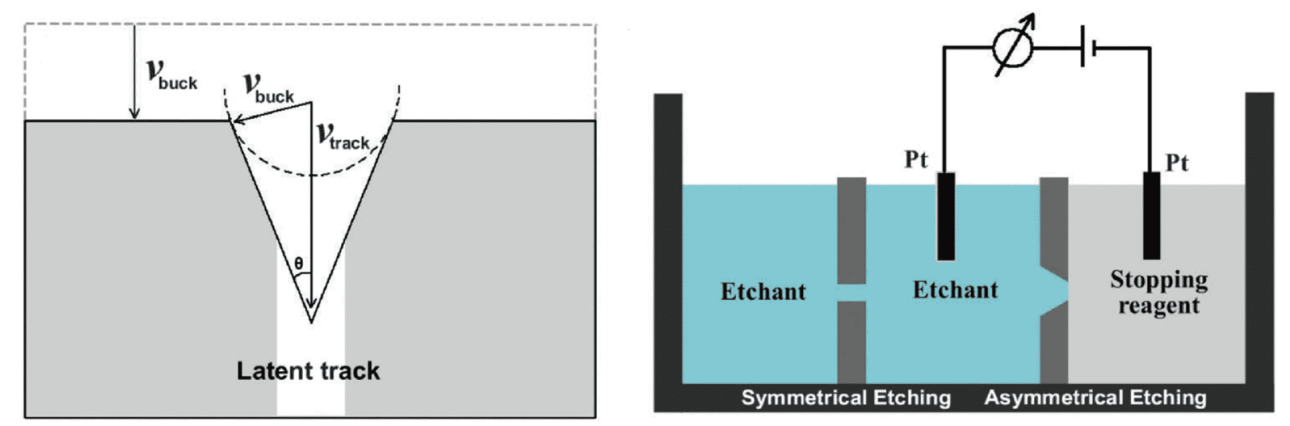

Figure 4 Schematic diagram of an etched ion track and simple schematic diagram of the etching conductivity device. Reprinted with permission from Ref. [3], Copyright 2001, Elsevier Science B.V.

and $\mathrm{KCl}$ or a mixture of $\mathrm{KCl}$ and $\mathrm{HCOOH}(1: 1$ by volume) is used as the terminating agent $[72,73]$; for polyimide (PI), the main reagent for oxidation etching is $\mathrm{NaClO}$, and $\mathrm{KI}$ solution is used as the terminating reagent; for polycarbonate (PC), the typical etching condition for producing cylindrical holes is $6 \mathrm{~mol} \mathrm{~L}^{-1} \mathrm{NaOH}$ at $50^{\circ} \mathrm{C}$ [3]. The tapered nanochannel can be obtained by changing the process conditions, such as adding $20 \%-$ $30 \%$ methanol to the $9 \mathrm{~mol} \mathrm{~L}^{-1} \mathrm{NaOH}$ solution [74] or increasing the working voltage during the etching process. The pore density of nanochannels depends on the number of incident irradiated ions. By selecting the appropriate etching solution, temperature and etching time, the diameter of the produced nanochannel can be controlled [75] within the range of several nanometers to several microns. Moreover, the chemical etching condi- tions also determine the specific shape of the nanochannel.

PET membranes have significant advantages over other membranes and have been used to study the physical property of ion transport across membranes [76,77]. The etching process is very simple, and at the same time, the diameter of the nanochannel can be easily controlled by changing the conditions [78]. In addition, the PET surface can be etched by high-concentration sodium hydroxide and generates carboxyl groups in situ, which can be used for further modification [79]. PET nanochannels can be used to manufacture various nanodevices in response to various stimuli, such as specific ions and molecules $[25,66,80-86], \mathrm{pH}[65,67,68,87-90]$, temperature [91,92], and multiple stimuli [11,56,60,93-95] (Table 1). For example, inspired by the light/pH-switched 
Table 1 The functional group for various nanodevices in response to various stimuli

\begin{tabular}{|c|c|c|c|c|c|}
\hline Stimuli & & Functional groups & Stimuli & & Functional groups \\
\hline \multirow{5}{*}{$\mathrm{pH}$} & & Chondroitin-4-sulfate (ChS) [96] & \multirow{5}{*}{ Temperature } & & Pillar[5]arene [97] \\
\hline & & Poly(acrylic acid) (PAA) [88] & & & PNIPAAm-co-PBA [22] \\
\hline & & Polydopamine [98] & & & Poly(benzyl methacrylate) (PBzMA) [99] \\
\hline & & Histidine [100] & & & PNIPAAm [91] \\
\hline & & Polyelectrolyte (PE) [101] & & & Elastin-like polypeptide (ELP) loops \\
\hline \multirow{4}{*}{ Light } & & Azobenzene (Azo)-DNA [103] & \multirow{4}{*}{ Ion } & $\mathrm{UO}^{2+}$ & $\begin{array}{l}\text { 4-Amino benzamidoxime } \\
\text { (ABX) }[104]\end{array}$ \\
\hline & & $\begin{array}{l}\text { C4-DNA motors and malachite green } \\
\text { carbinol base (MGCB) }[105]\end{array}$ & & $\mathrm{Ca}^{2+}$ & $\begin{array}{l}\text { Poly }[(N \text {-isopropylacrylamide-co-4- }(3- \\
\left.\text { acryloylthioureido }) \text { acid })_{0.2}\right](\text { PNI-co- } \\
\left.\text { ATBA }_{0.2}\right)[106]\end{array}$ \\
\hline & & Spiropyran [107] & & $\mathrm{Pb}^{2+}$ & $\begin{array}{l}\text { 4'-Aminobenzo-18-crown-6 } \\
\text { (4-AB18C6) }[80]\end{array}$ \\
\hline & & Azobenzene ligands [108] & & $\mathrm{Hg}^{2+}$ & $\begin{array}{l}\text { mercaptoacetic acid-pillar[5]jarene } \\
\text { (MAP5) [81] }\end{array}$ \\
\hline \multirow{4}{*}{ Molecule } & CAMP & $\begin{array}{l}\text { Poly }(N \text {-isopropylacrylamide-co- }(\mathrm{S}) \text { - } \\
\text { (4-acrylamido-1,2,3-triazol)-5- } \\
\text { guanidino-pentanoic acid) }[32]\end{array}$ & \multirow{4}{*}{ Multi } & $\begin{array}{l}\text { Temperature, } \mathrm{pH} \\
\text { and sugar }\end{array}$ & $\begin{array}{l}\text { poly[2-(dimethylamino) ethylmethacry- } \\
\text { late]-co-[4-vinyl phenylboronic acid] } \\
(\mathrm{P}(\mathrm{DMAEMA}-\mathrm{co} \text {-VPBA }))[109]\end{array}$ \\
\hline & $\begin{array}{l}\text { Bovine serum } \\
\text { albumin }\end{array}$ & $\mathrm{TiO}_{2}$ and cysteine enantiomers [110] & & $\mathrm{pH}$ and temperature & PNIPAAm and PAA [56] \\
\hline & Cocaine & $\begin{array}{l}\text { Capture DNA aptamers } \\
\text { (C-aptamers) }[25]\end{array}$ & & $\mathrm{Na}^{+}$and $\mathrm{K}^{+}$ & $\begin{array}{l}\text { 4'-Aminobenzo-15-crown-5 and 4'- } \\
\text { aminobenzo-18-crown-6 [27] }\end{array}$ \\
\hline & MicroRNAs & $\begin{array}{l}\text { Phosphorodiamidate } \\
\text { morpholino oligos [111] }\end{array}$ & & $\mathrm{Hg}^{2+}$ and $\mathrm{Ag}^{+}$ & $\begin{array}{l}\text { T-/C-rich single-strand DNA (ssDNA) } \\
{[20]}\end{array}$ \\
\hline
\end{tabular}

channelrhodopsin-2 (ChR2) ionic gate in mammalian cells (Fig. 5a), Xiao et al. [94] grafted an environmental stimulus-responsive molecule 8-hydroxypy-1,3,6-trisulfonate (HPTS) onto the solid-state nanochannel, and prepared a light and $\mathrm{pH}$ cooperative stimuli ionic gate. The single conical-shaped PET nanochannel was prepared by a common method (Fig. 5b) and the modification process was carried out by a two-step reaction. With coupling reaction between the carboxyl groups on PET and the amino groups of ethylenediamine (EDA), EDA can be grafted onto the inner surface of the nanochannel. Then, they further grafted HPTS onto the nanochannel modified by electrostatic interaction with EDA (Fig. 5c). The HPTS-modified nanochannel displayed four gating states from open to close under different $\mathrm{pH}$ and light conditions (Fig. 5d).

Although PI films [97,112-114] were not applied as frequently as PET films, PI nanochannels can provide a highly stable ion current signal $[115,116]$ and high surface charge density [54] comparable to PET. For example, Guo et al. [117] demonstrated the salinity gradient energy harvesting on a non-biological single channel nanofluidic with PI membrane, and achieved ultrahigh power density. In addition, two more common polymer materials are introduced, $\mathrm{PC}$ and polyethyleneimine (PEI). Deng et al.
[118] used polyvinyl alcohol (PVA) to modify the tracketched PC (TEPC) membranes and constructed a biomimetic nanodevice for cascade response of borate and cis-hydroxyl compounds. Morones-Ramírez [11] grafted opt-thermally responsive polymer-nanoparticle nanocomposites onto the PC track-etched porous membrane, realizing the engineering design, mathematics modeling and manufacturing of a reversible fast-responding porous membrane. Lokuge et al. [119] reported that the nanocapillary array membrane (NCAM), prepared by modifying poly( $N$-isopropylacrylamide) (PNIPAAm) brushes onto the surface of Au-coated PC, achieved adjustment of the effective pore size towards temperature response. PEI usually functions as the responsive groups in bioinspired nanochannels. For example, Li et al. [83] prepared responsive polymer PEI-g-glucopyranoside (Glc-PEI)modified nanochannels (Fig. 6a, b), which are promising for developing the device with high sensitiveness to sialylated glycans (Fig. 6c).

The track etching method to prepare nanochannel is usually limited by equipment. The functional groups are usually modified additionally. In this review, we summarized more methods such as casting, vacuum filtration, self-assembly, electrospinning, and phase separation for constructing nanochannels. The combination of casting 

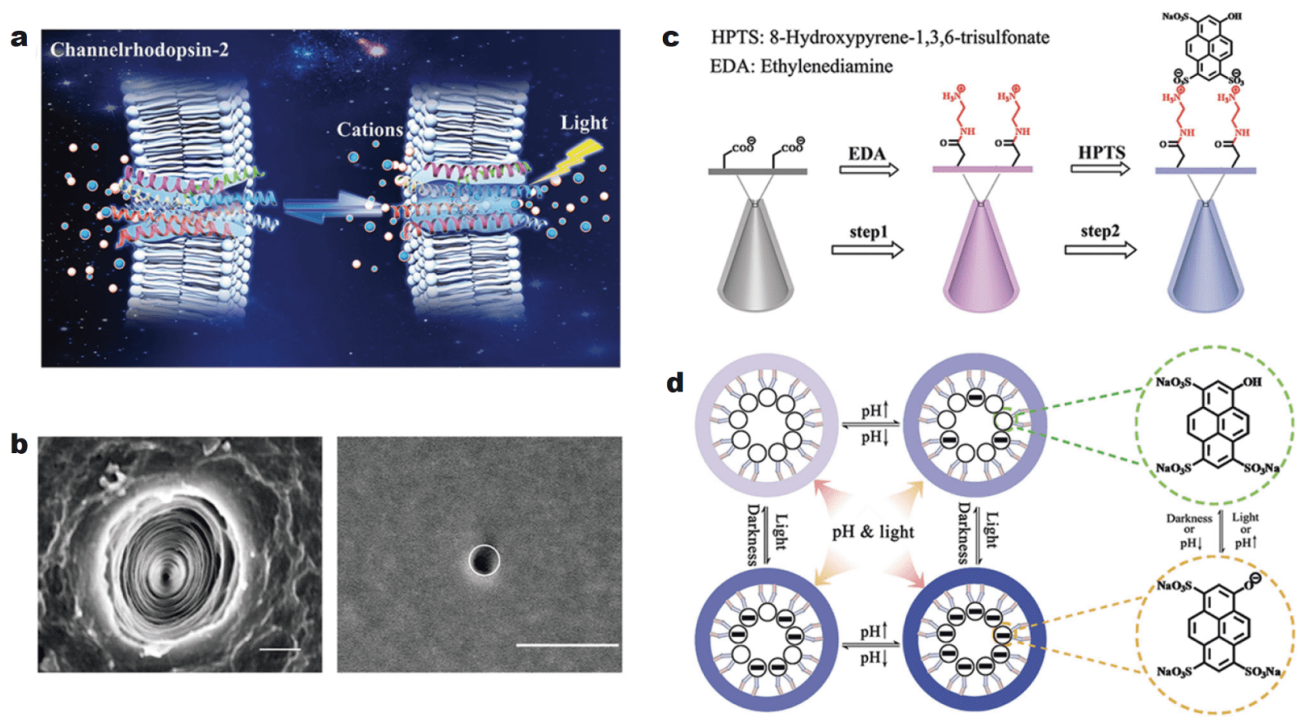

Figure 5 (a) Scheme of the biological ChR2 gate. (b) Base side and tip side scanning electron microscopy (SEM) of the conical PET single nanochannel. Scale bar: $200 \mathrm{~nm}$ (left) and $100 \mathrm{~nm}$ (right). (c) The preparation process of HPTS-modified nanochannel. (d) Four gating states under different $\mathrm{pH}$ or UV light stimulations. Reprinted with permission from Ref. [94], Copyright 2014, WILEY-VCH Verlag GmbH \& Co. KGaA, Weinheim.
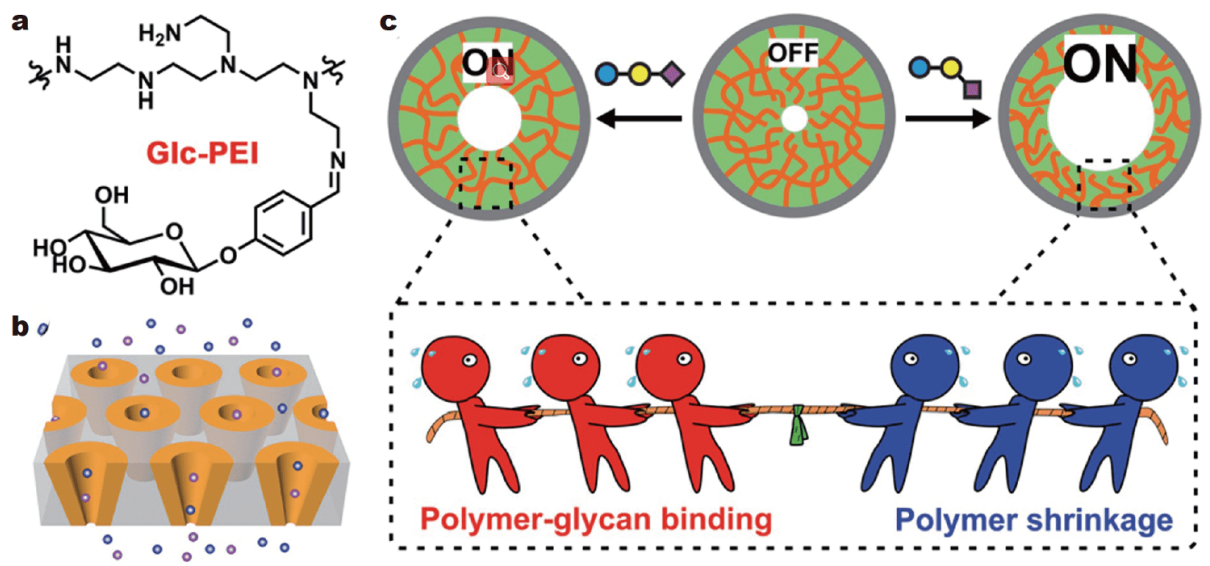

Figure 6 (a) Chemical structure of Glc-PEI. (b) Schematic of the Glc-PEI-modified nanochannels. (c) Glycan-induced nanochannel "OFF-ON" gates, showing the competition between polymer-glycan binding and the polymer shrinkage. Reprinted with permission from Ref. [83], Copyright 2020, Royal Society of Chemistry.

and phase separation is a facile strategy to construct nanochannels. For example, Zhu et al. [120] designed and synthesized a Janus membrane based on two ionomers with tunable surface charge density and porosity (Fig. 7a). They firstly synthesized positively charged poly(ether sulfone) with pyridine pendants (PES-Py) and negatively charged hexasulfonated poly(aryl ether ketone) (PAEKHS) [121]. Then, the Janus membrane can be achieved by spin-coating these polymers sequentially. By tuning the contents of the ionomers, the nanochannel membranes with different pore sizes and porosities can be obtained, which was applied for energy conversion, and achieved $2.66 \mathrm{~W} \mathrm{~m}^{-2}$ output power density. Zhao et al. [122] synthesized a sulfonated poly(ether ether ketone) (SPEEK) nanochannel membrane involving numerous nanochannels by utilizing nonsolvent induced phase separation (NIPS) technique (Fig. 7b). The membranes, which have been charged negatively, include a spongy porous layer as the supporting agent and also a dense shell layer, which is plenteous in parallel contiguous nanochannels. 


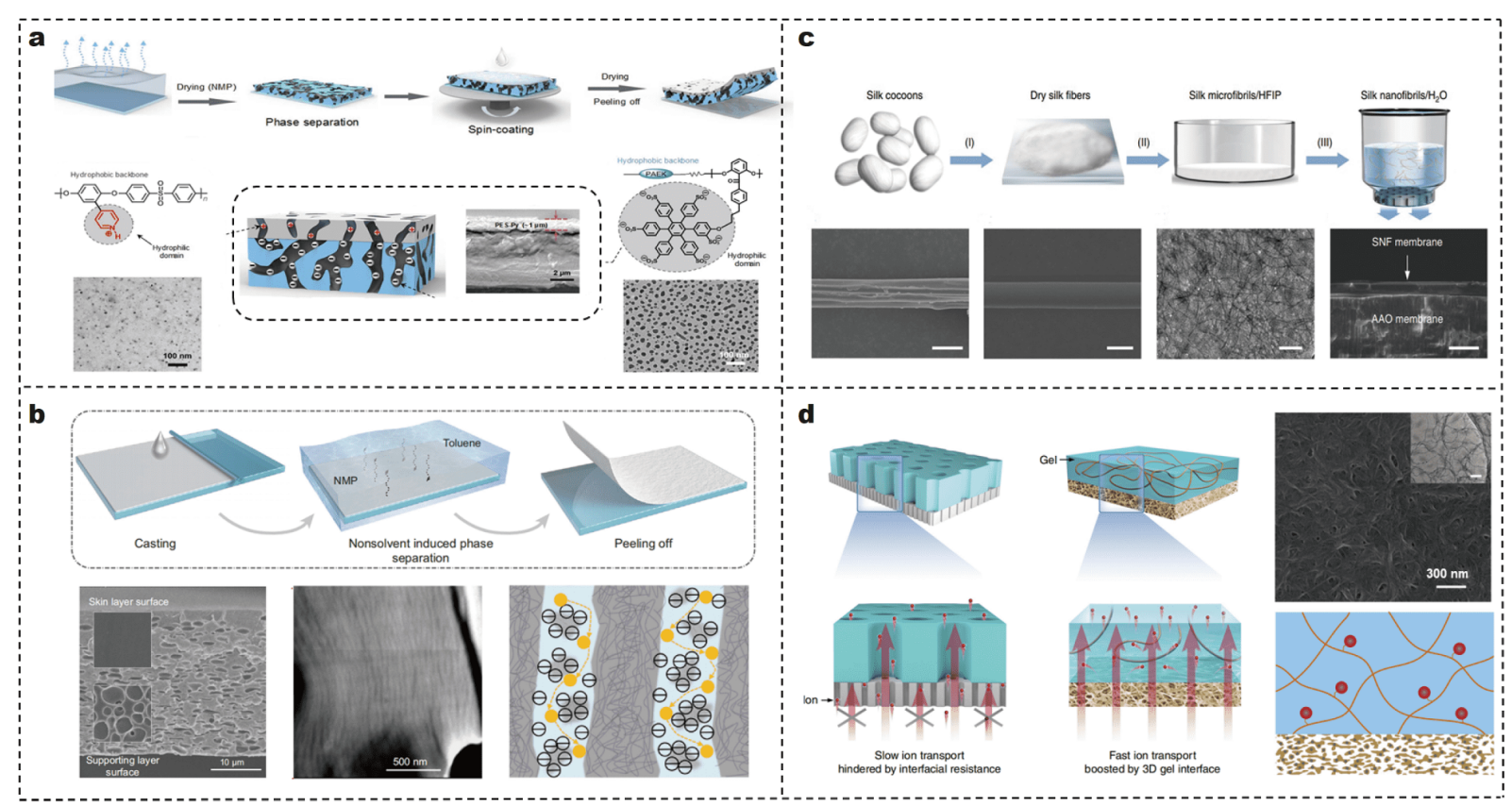

Figure 7 (a) Preparation process of the Janus polymer membrane by combining PES-Py (left) and PAEK-HS (right). Reprinted with permission from Ref. [120], Copyright 2018, American Association for the Advancement of Science. (b) Fabrication of the asymmetric SPEEK membrane with the thin skin layer and supporting layer. Reprinted with permission from Ref. [122]. (c) Schematic fabricating process of silk nanofibril/AAO membranes. SEM image of natural silk cocoons, degummed silk fiber, transmission electron microscopy (TEM) image of silk nanofibril with a diameter of $\sim 20 \mathrm{~nm}$ and cross-sectional of the hybrid membrane (from left to right). Scale bars from left to right: 20, 2.5, 0.2 and10 $\mu$ m. Reprinted with permission from Ref. [123], Copyright 2019, Springer Nature. (d) 3D hydrogel membrane for ion transportation. Reprinted with permission from Ref. [126], Copyright 2020, Springer Nature.

The parallel nanochannels with great space charges exhibit magnificent cation-selectivity, which is able to be enhanced via modifying the charge density and length of nanochannels. In addition, the SPEEK membranes divulged desirable mechanical features, rendering the possible creation of membranes with high-endurance scaleup property.

More functional polymers such as biological polymers, BCPs, and hydrogels are developed in recent years. For example, bombyx mori (silkworm) silk is a natural polymer material with many excellent properties, such as abundant surface groups, excellent mechanical properties, and easy modification with functional groups. Xin et al. [123] prepared a silk-based hybrid membrane and applied it for energy conversion. The results showed that the membrane performed good energy conversion efficiency and long-term stability. The author used a variety of solvents to dissolve the sericin wrapped around the silk to obtain the required nanofibers (Fig. $7 \mathrm{c}$ ). Then, the silk membrane was fabricated by vacuum filtration. The silk nanofibril membrane with negative surface nanochannels was suitable for ion transport. Furthermore, Chen et al.
[124] constructed a silk fibroin membrane through the spin coating method within three layers. The prepared silk fibroin membrane could be simply regulated by adjusting the layers of the membrane. Electrospinning is a well-established method for preparing fibrous $3 \mathrm{D}$ material for constructing nanochannel membranes [125].

To make further improvement of ion transport efficiency in the interface, they presented the use of $3 \mathrm{D}$ polyelectrolyte hydrogel on the research of ion transport $[126,127]$. The hydrogel membrane can provide a charged $3 \mathrm{D}$ network for ion transportation, and the interface transmission efficiency can be greatly improved (Fig. 7d) $[128,129]$. Schroeder et al. [130] introduced polyacrylamide hydrogel compartments consisting of cationand anion-selective hydrogel. They used it as an electriceel-inspired soft power source, generating total opencircuit potential up to $100 \mathrm{~V}$ and power densities of $27 \mathrm{~mW} \mathrm{~m}^{-2}$ per gel cell. Chen et al. [129] used 2-hydroxyethyl methacrylate phosphate (HEMAP) which was negatively charged as the key monomer and synthesized a hydrogel film by using space-charged and 3D interconnected nanopores through the photopolymerization 
method. This HEMAP hydrogel membrane performed great conductivity as well as magnificent energy conversion behavior.

\section{Block copolymer nanochannels}

BCPs play a key role in the construction of nanochannels [87]. BCP self-assembly technology has been developed as one of the most promising methods for preparing porous polymers with well-ordered nanochannel structures and tunable sizes [131]. BCP is a special polymer prepared by connecting two or more polymer segments with different properties together. They have thermodynamic incompatibilities between different polymer chains $[132,133]$, displaying unique phase separation structure. Compared with other nanochannel materials, amphiphilic BCP membranes show great advantages due to their diverse and multifunctional macromolecular blocks $[131,134]$. These mobile, stable and extensible macromolecular groups perform as intelligent effectors [135138], for energy conversion and storage [87,139], responsive gating $[93,134]$ and other fields $[10,140]$.

Functional BCP to prepare ordered nanochannels is the key to achieve high-performance ion transport. Our group designed the functional BCP with the chalcone liquid crystal element to chemically crosslink continuous phase and nitrobenzyl ester structure capable of degradation under ultraviolet (UV) light. Thus, we successfully prepared large-scale membrane with excellent mechanical strength and well-defined nanochannel structure $[4,139,141]$. The molecular design concept is as follows: (1) the design of liquid crystal polymer. The liquid crystal segment should stabilize and maintain the nano-ordered structure during the self-assembly process of the BCP, which is important for membrane up-scaling. (2) Design of cross-linkable groups. Since the chalcone structure can undergo a " $2+2$ " cycloaddition reaction under UV irradiation, this structure is introduced into crystal structure and to crosslink the continuous phase, which would improve the mechanical strength and stabilize the nanostructure. (3) The design of degradable groups. Two separate polymer chains are chemical bonded by the nitrobenzyl ester structure, which would be degraded by UV light and generate carboxylic acid in situ. In addition, the UV conditions of the chalcone cycloaddition reaction and the degradation reaction of nitrobenzyl ester are the same. The cross-linking of the block and the bond cleave of the connection point can be achieved simultaneously in a "one-step" method. (4) Design of the flexible section. The flexible section is polyoxyethylene (PEO) with good solubility in lots of solvents. It can be easily cleaned from the nanostructure after breaking the chain, which benefits the formation of nanochannels in the film.

Based on the above design ideas, we reported an organic-inorganic hybrid nanochannel using a BCP and AAO (Fig. 8a). It has the characteristics of nanofluid diodes in a wide $\mathrm{pH}$ range [137], and displays a high energy conversion efficiency over a wide $\mathrm{pH}$ range [4]. To improve the performance, our group prepared an ultrathin and ion-selective Janus membrane using phase separation of BCPs (Fig. 8b, c) [139]. The membrane can convert osmotic energy with high power density by mixing natural seawater and river water [142], which provides a new idea for constructing high-energy ion
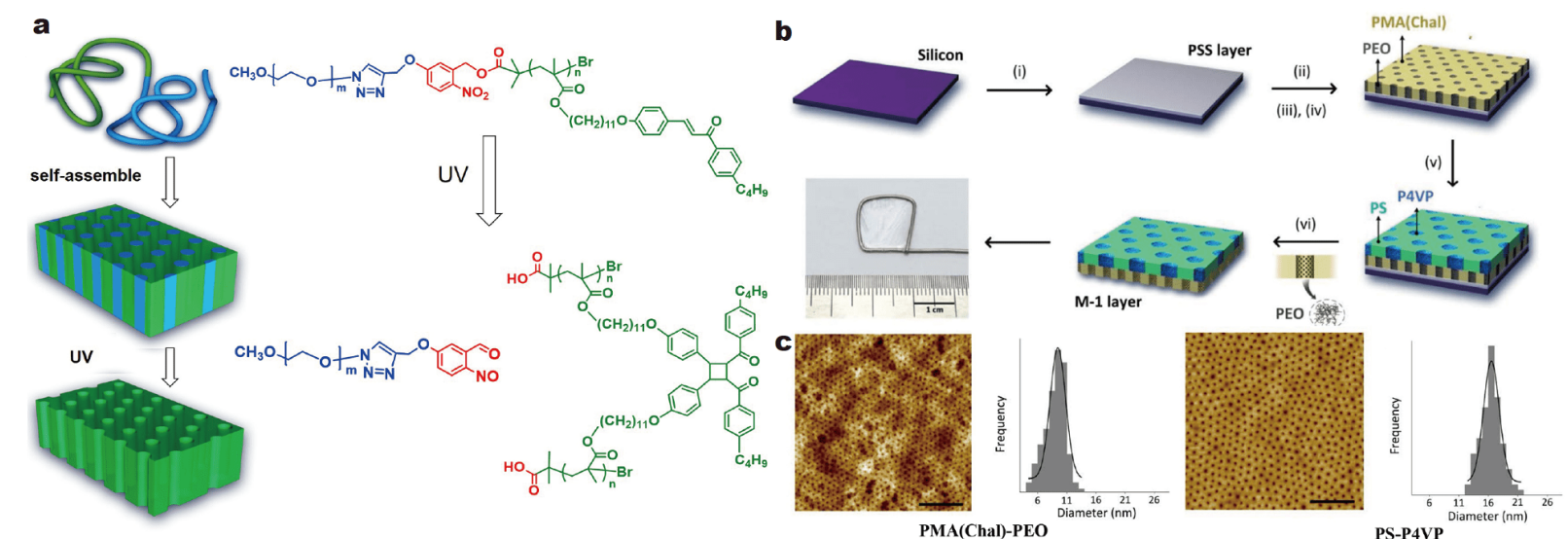

Figure 8 (a) The BCP-based nanochannels prepared by self-assembly and UV degradation. The BCP molecule contains a UV-degradable linker between the blocks and UV-crosslinkable chalcone groups in one block. Reprinted with permission from Ref. [4], Copyright 2019, American Chemical Society. (b) Fabrication process of the ultrathin ion-selective Janus membrane based on BCPs and atomic force microscopy (AFM) images of the back side (left) and front side (right) of the Janus membrane (c). Reprinted with permission from Ref. [139], Copyright 2017, American Chemical Society. 
concentration battery [143]. The bottom-up preparation scheme can also realize ultra-density nanochannel arrays, overcoming the channel density limit of the top-down designed membranes in the past $[40,68,144,145]$. Obviously, BCPs have made breakthroughs in osmotic energy conversion, and have also achieved good results in other aspects, such as reversible $\mathrm{pH}$ response behavior [134], multiple response characteristics [93], which are introduced in subsequent chapters.

Fig. 9 shows the time line of bioinspired polymer nanochannels. Etched polymer nanochannels play an important role in the early stage of the development of biomimetic nanochannels [146-149]. Recently, more and more methods and materials are developed to satisfy more demands in application.

\section{APPLICATIONS}

\section{Responsive channels}

The development of nanochannels responding to external stimuli like $\mathrm{pH}$, temperature, light, ions, molecules, and multiple stimuli has made rapid progress in recent years. We illustrate the ion regulation of nanochannels by the common stimuli in the following sections.

\section{pH-responsive nanochannels}

Presently, $\mathrm{pH}$-responsive nanochannels are the most extensively studied $[3,150]$. There are two major reasons: (1) the first one is the wide applicability along with their high application value. This is due to that $\mathrm{pH}$ is a very important parameter for all the electrochemical reactions. It is considered as an important indicator of biochemical changes taking place in the ion channels of the living system $[13,14,40]$. (2) The second reason is the relatively simpler construction of $\mathrm{pH}$-responsive channels $[9,151]$. Among the various materials used for the construction of $\mathrm{pH}$-responsive channels, polymeric materials are widely applied. As early as in 2003, Siwy's group [70] constructed single asymmetric nanopores such as PET and PI films with carboxy groups using the track etching technology. It was found that the electrolyte has different rectification phenomena in presence of different $\mathrm{pH}$ values, clearly indicating that these nanopores have obvious pH-responsive properties. Zhang et al. [60] grafted two polyelectrolytes with opposite $\mathrm{pH}$ responses to the left and right tips of a cigar-shaped nanochannel, constructing an ion pump with a cooperative $\mathrm{pH}$-responsive double-gate nanochannel. The two electrolytes are polyelectrolyte-polyvinylpyridine (PVP) and polyacrylic acid (PAA). The swelling and collapse state of the nanochannel can be controlled by adjusting the $\mathrm{pH}$ value, and then the opening and closing of the channel can be controlled (Fig. 10a). Because PVP and PAA have functional groups with opposite charges [40,63], these reverse $\mathrm{pH}$-responsive conformational transitions can well induce the on/off, off/on, on/off, and off/off gating states of the PVP/PAA gate, thereby producing three unique ion migration characteristics of the bio-ion pump.

Zhao et al. [96] prepared pH-regulated nanochannels by a layer-by-layer self-assembly method utilizing PEI and chondroitin-4-sulfate (CHS), which is a good example for the use of polyelectrolytes to achieve specific functions. The polyelectrolyte CHS, which has two anionic functional groups, i.e., sulfonic and carboxyl groups, can be strongly adhered to the branched PEI. The experimental result shows that when the salt concentration

\section{Bioinspired polymer nanochannels}

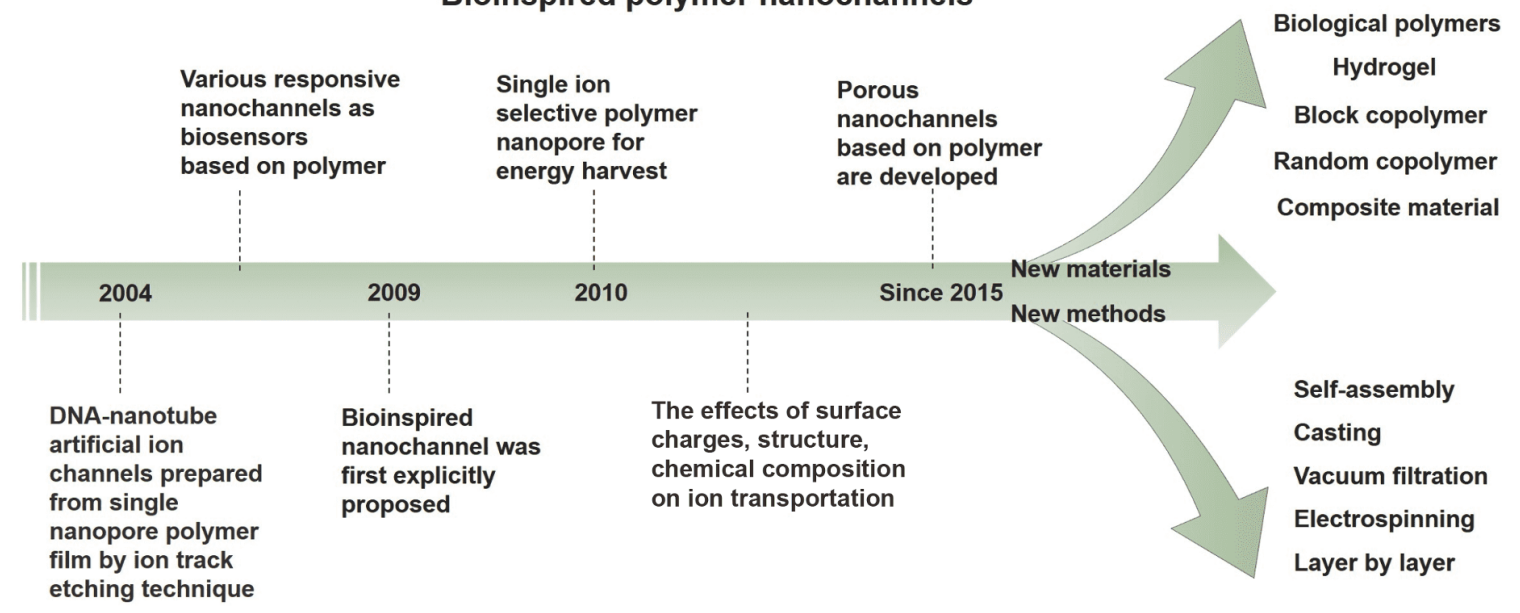

Figure 9 The time line for the development of bioinspired polymer nanochannels. 


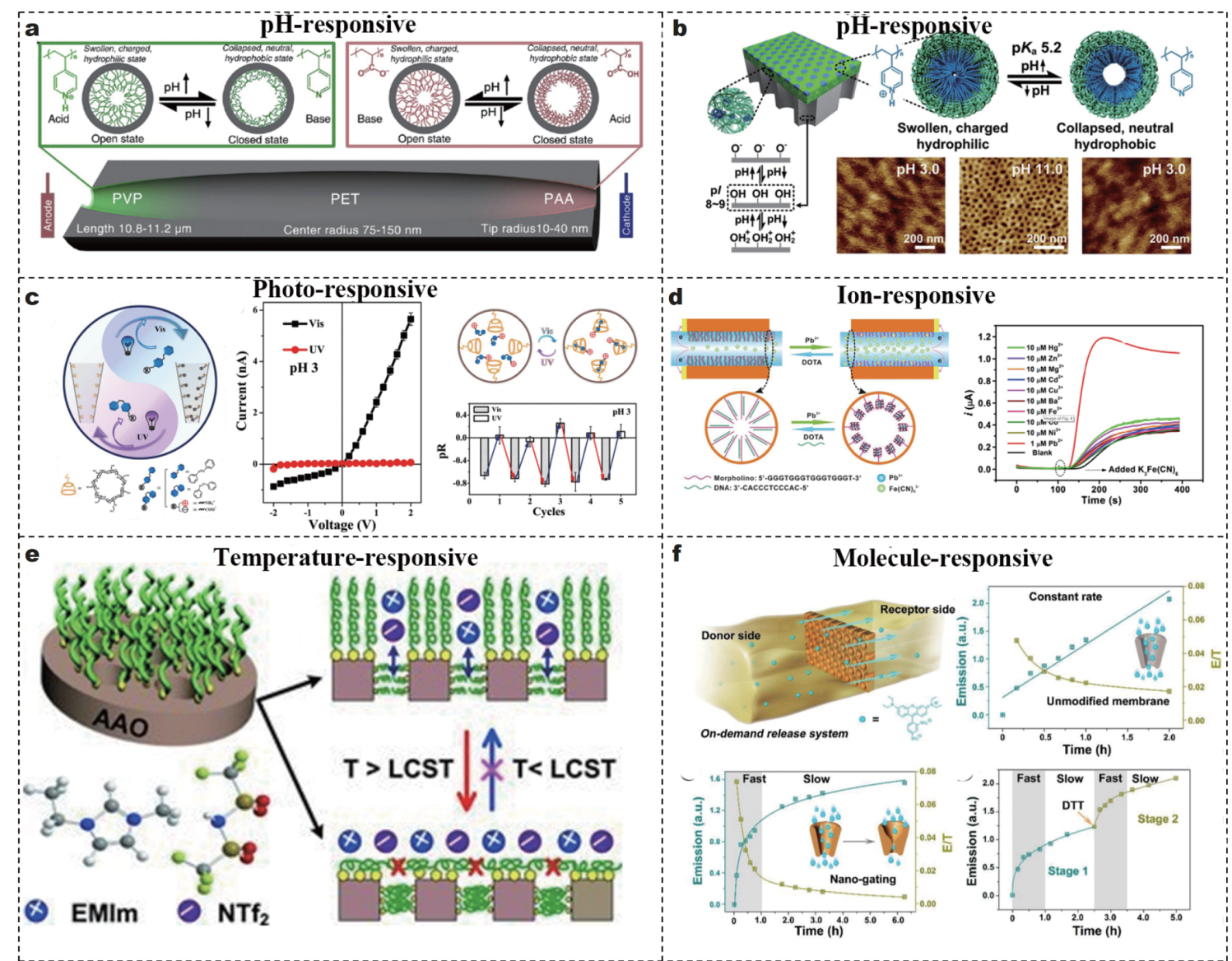

Figure 10 (a) Cross-sectional schematic of the pH-responsive double-gate nanochannel in which acid-driven PVP gate and alkali-driven PAA gate are grafted on the two sides of the channel, respectively. Reprinted with permission from Ref. [60], Copyright 2013, American Chemical Society. (b) Schematic of reversible $\mathrm{pH}$-responsive behavior of the BCP nanochannels and AFM images of the BCP membrane at different $\mathrm{pH}$ values. Reprinted with permission from Ref. [134], Copyright 2015, WILEY-VCH Verlag GmbH \& Co. KGaA, Weinheim. (c) Schematic diagram of controlling functional groups in nanochannels through photoresponsive host-guest interaction. Reprinted with permission from Ref. [113], Copyright 2018, Springer Nature. (d) Scheme of the sensing principle for $\mathrm{Pb}^{2+}$ detection and the ion selectivity of the morpholino-DNA-functionalized PAA membrane. Reprinted with permission from Ref. [183], Copyright 2015, Elsevier B.V. (e) Above the lower critical solution temperature (LCST) in ionic liquid electrolyte $\left([\mathrm{EMIm}]\left[\mathrm{NTf}_{2}\right]\right)$, the polymer brushes with conformational collapse will block the pathway for ion transportation. Reprinted with permission from Ref. [99], Copyright 2012, WILEY-VCH Verlag GmbH \& Co. KGaA, Weinheim. (f) Schematic illustration of the on-demand release system and the time-concentration curves of molecules transporting through nanochannels. Reprinted with permission from Ref. [84], Copyright 2018, Wiley-VCH Verlag GmbH \& Co. KGaA, Weinheim.

is low, the nanopores are almost closed at $\mathrm{pH}>4$, and the gate is open to anions only at lower $\mathrm{pH}(<4)$. Moreover, the $\mathrm{pH}$ response of the nanochannel disappears with increasing salt concentration. Further, significant results have also been achieved in the domain of $\mathrm{pH}$ responsive nanochannels using BCPs $[87,95,134,152,153]$. Zhang et al. [134] combined asymmetric BCP and porous anodic aluminum oxide to prepare a multifunctional heterogeneous membrane, showing an obvious $\mathrm{pH}$ response. Apart from utilizing the high mechanical strength of the inorganic material, this heterogeneous membrane is also able to overcome the inherent defect of the inorganic material having monotonous functional group. Fig. 10b shows that when the inner wall of the nanochannels ( $\mathrm{pKa}$ $\approx 5.2$ ) containing poly(4-vinylpyridine) (P4VP) chains are exposed to a solution with a $\mathrm{pH}$ value lower than 5.2, they become swollen, positively charged, and hydrophilic. Otherwise, they are in collapsed, neutral and hydrophobic states [154,155], clearly indicating the $\mathrm{pH}$-responsive characteristic of the nanochannels $[134,156]$.

\section{Photo-responsive nanochannel}

Compared with the other responsive channels, photoresponsive nanochannels have certain unique advantages. 
First, light can be quickly turned on or off $[107,113,155]$, and thereby achieving precise control of the nanochannels; second, higher space-time accuracy of the light-responsive channels [157] due to precise projection ability of light; third, since the light can penetrate through the tissues, the remote and non-invasive in-situ control can be achieved $[158,159]$, which minimizes the invasiveness and potential damage to the subject. Spiropyran $[107,160]$, azobenzene $[108,113,158,161]$ malachite green derivatives [105] are some of the common light-responsive molecules. Liu et al. [113] utilized the host-guest interaction between azobenzene and $\beta$-cyclodextrin to construct a photo-responsive nanochannel based on PI membrane (Fig. 10c). When irradiated by visible light, the azo group bonded with $\beta$-cyclodextrin $(\beta-C D)$ and transformed into the trans conformation, resulting in an increase in positive charge. Consequently, there was an increase in the ion current from 0.065 to $5.65 \mathrm{nA}$ at $\mathrm{pH} 3$ under a positive voltage $(+2 \mathrm{~V})$. However, the ion current recovered to $\sim 0.065 \mathrm{nA}$ when UV irradiation was carried out, because the azo group was converted to a cis conformation and peeled off the pore surface. The nanofluidic diode realizes reversible switching based on the light response after being irradiated by visible or UV light, and also shows good stability and reversibility.

However, poor biocompatibility of these photochromic molecules (spiropyran, azobenzene, malachite green derivatives) severely limits their further applications [162]. In this regard, DNA is considered as an excellent candidate by its supramolecular property of duplex formation through complementary pairs [163,164]. As a special polymer, DNA molecule in photo-responsive nanochannels has wide range of applications. Wen et al. [105] grafted C4-DNA motors onto a PET membrane and achieved photo-responsive characteristic. The conformation of DNA changed via receipt or release of protons generated by UV radiating the malachite green methanol base (MGCB). The film was repeatable as well as stable in nature even after many cycles of alternate measurements under UV and dark conditions. Li et al. [162] obtained a new type of functional nanochannel via integration of the Azo-DNA strands with the PET film. The nanochannel displayed short response time and reversibility as other light-responsive devices. Besides, it also had the advantages of good biocompatibility and universal design [165], with the potential for use in light-controlled drug release and other fields [166].

Ion-responsive nanochannels

Diverse ion-responsive nanochannels such as $\mathrm{K}^{+}$
$[112,167], \mathrm{Pb}^{2+}[80], \mathrm{Zn}^{2+}[66,86,168,169], \mathrm{Ca}^{2+}[106,170]$, $\mathrm{Hg}^{2+}$ [81], and $\mathrm{Cl}^{-}$[171] have been investigated in the recent years. Yang et al. [104] prepared a single conical nanochannel from 4-amino benzamidoxime $(\mathrm{ABX})$ and PI membrane. This channel has detection ability for ultratrace uranyl ions in a complex environment with simultaneous uranyl removal properties [172-175]. Furthermore, a $\mathrm{Zn}^{2+}$-responsive nanochannel based on the salicylaldehyde Schiff base (SASB) was prepared by Sun $e t$ al. [66]. This channel can not only provide an effective and reversible "on/off" state, but also can be modified unilaterally. This provides a greater experimental basis for further promotion of the asymmetric chemical modification of molecules with various complex functionalities.

In addition, label-free DNA analysis has been widely used in biochemical analysis [176-179]. Researchers have proposed various amplification strategies to improve the high-sensitivity analysis of DNA in nanochannels [180182]. One of the strategies is to fix neutral biological probes (peptide nucleic acid (PNA), morpholino, etc.) with capture property in the nanochannel, and then use low ion intensity for amplifying the target signal to reduce the background signal [150-152]. Chen et al. [183] established a new type of $\mathrm{Pb}^{2+}$ bionic logic gate sensor via modification of a porous alumina membrane by morphine and DNA. Nanochannel devices functionalized with DNA can achieve the opening and closing of nanochannels by the use of 1,4,7,10-tetraazacyclododecane- $N$, $N^{\prime}, N, N^{\prime}$-tetraaceticacid (DOTA), and $\mathrm{Pb}^{2+}$, and have objective repeatability and stability (Fig. 10d).

\section{Temperature-responsive nanochannel}

PNIPAAm occupies an extremely important position in temperature-responsive nanochannels. Researchers have designed many temperature-sensitive channels by the sharp volume transition that occurs near the critical solution temperature of PNIPAAm [6,92,119]. Reber et al. [36] grafted PNIPAAm hydrogel onto the etched PET channel membrane, and studied the local transport characteristics by measuring the current of the single pore membrane, which provided a good example for studying the application of responsive membranes in the field of drug release. Lokuge et al. [119] prepared an NCAM by grafting PNIPAAm brush onto the outer surface of $\mathrm{Au}$ coated PC to achieve active controlled transport. Yameen et al. [6] proved that the PNIPAAm-modified PI membrane can act as thermally driven molecular gate with a closed stage, which can be remotely controlled by simple adjustment of the operating temperature in the range of 
23-40 ${ }^{\circ} \mathrm{C}$. Zhang et al. [22] constructed a macromolecular nanochannel system via grafting poly(NIPAAm-acid) onto the AAO solid-state nanochannel using the typical surface-induced atomic transfer radical polymerization (ATRP) process and explored the effect of the length of the gated molecule on its gating performance.

Zhou et al. [99] created a temperature-responsive nanochannel which can operate in room-temperature ionic liquid system by attaching the molecular brush of polybenzyl methacrylate (PBZMA) to the surface of the polymer via the surface-induced ATRP process. The conformational change of PBZMA molecular brush contributed to the thermal shutdown behavior of the modified nanochannel (Fig. 10e) [184]. The changes in electrical conductivity and the effective porosity of the channel with temperature indicate that the nanochannels have good thermal response characteristics. In addition, Wang et al. [97] constructed a temperature-sensitive artificial channel using the host-guest interaction of the Pillar[5] arene. The selectivity of ion transport can be converted from cation to anion by controlling the degree of host-guest binding via regulation of the temperature. This study not only opens up a new means for better understanding of the mechanism of temperature-sensitive characteristics, but also shows a broader prospect for biomedical research.

\section{Molecule-responsive nanochannel}

Molecule-responsive nanopores have attracted wide attention due to their possible applications in molecular recognition, biosensors and drug separation $[9,13,14,151]$. The core element of the sensor nanofluidic device is the control of the transmission of the nanochannels via utilizing their specific interactions $[44,185]$. The specific interaction between the target ion or molecule and the functional group fixed on the surface of the channel is responsible for the change of the ion current of the responsive channel [186-188]. Most interaction processes are based on non-covalent bonds, such as electrostatic interactions, and hydrogen bonds [189-191]. However, due to these weak non-specific interactions, subtle interference with ligands on the channel surface may reduce the accuracy of the response to specific ions or molecules. Consequently, these systems cannot guarantee good accuracy in complex matrices and real environments.

Sun et al. [73] developed bioinspired nanochannels with high Cys specificity and sensitivity by a click reaction strategy. The results show that the channel selectivity is very high even in the presence of complex substrates (interfering substances such as Arg, Asp, PHE, Met, Trp, Ser, His, Pro, Leu, Ala, Thr, Val, Lys, Tyr, Glu, AA, UA). In addition, due to the presence of strong covalent bonds [192], the channel can also achieve a highly specific response in complex environments and actual samples. This nanochannel was used for detecting different concentrations of Cys in urine samples [193], with no significant alteration of the current change ratio of Cys being observed in urine samples in comparison to that in the electrolytes resulting in a standard error of $\sim 2.51 \%$. Therefore, this channel achieves high Cys selectivity and strong non-interference in complex matrices and human urine. Though various triggering systems have been constructed [194,195], these systems can only control the transmission of molecules in burst mode rather than controlling the continuous transmission performance. In order to satisfy the clinical translation, a release system with on-demand, reproducible, repeatable and controllable molecular transport is required to be developed. Xiao et al. [84] introduced peptides as gatekeepers on the inner surface of PET film, which was able to achieve ondemand molecular transport based on the response characteristics of peptides to dithiothreitol (DTT). The process of on-demand release of molecules can be evaluated by measuring the flux rate of fluorescein between the two reservoirs (Fig. 10f). For the unmodified nanochannel membrane, there was a linear increase of the fluorescence intensity. However, the change in fluorescence intensity for the nano-gating system was different with sharp increase in the first $2 \mathrm{~h}$ followed by slowing down. The data of the release amount and release rate also directly indicated that the channel can achieve molecular control at an adjustable rate and dose-controlled release.

\section{Multi-responsive nanochannel}

The biological ion channels in nature usually respond to a variety of physical and chemical stimuli, which are crucial in physiological processes. Inspired by this, scientists have developed intelligent multifunctional responsive nanochannels and made breakthroughs in the fields of controlled drug release $[9,84,196]$, random DNA sequencing [197-199], and molecular recognition [46,84,114,200202]. For example, Guo et al. [186] synthesized a temperature- and $\mathrm{pH}$-responsive nanochannel by grafting poly(NIPAAm-co-acrylic acid) brush onto the inner wall of a tapered polyimide $[186,193,203]$. The current-voltage $(I-V)$ curves show different behaviors at different temperatures and $\mathrm{pH}$ values, indicating obvious $\mathrm{pH}$ - and temperature-responsive behaviors of the nanochannel. In 
addition, the authors evaluated the influences of NIPAAm and acrylic acid contents in the copolymer on the gate ratio and current rectification ratio. DNA as a special polymer has also been studied for multi-responsive nanochannels. We all know that mercury and silver are the two most toxic metal ions existing in the natural environment, posing huge danger to the health of the human being. Accurate and sensitive measurement of the $\mathrm{Hg}^{2+}$ and $\mathrm{Ag}^{+}$ ion concentrations has always been a hot topic. Studies have found that stable metal-ion-mediated base pairs are formed by the $\mathrm{Hg}^{2+}$ and $\mathrm{Ag}^{+}$ions in combination with specific nucleotide bases. Based on these characteristics, Wang et al. [20] designed a new type of bionic ion-responsive nanochannel via immobilization of singlestranded DNA (ssDNA) in a funnel-shaped alumina nano-channel (Fig. 11a). They selected a series of interfering ions for comprehensive experimental analysis, including $\mathrm{Zn}^{2+}, \mathrm{Mg}^{2+}, \mathrm{Fe}^{2+}, \mathrm{Fe}^{3+}, \mathrm{Cd}^{2+}, \mathrm{Pb}^{2+}, \mathrm{Mn}^{2+}$ and $\mathrm{Cr}^{2+}$ ions. The results show that the nanochannel still has good selectivity to $\mathrm{Hg}^{2+}$ and $\mathrm{Ag}^{+}$in a complex environment (Fig. 11b, c).

The use of BCPs in the multi-responsive nanochannels has been reported. Zhang et al. [93] demonstrated the construction of a functional nanofluidic system using the confined swelling-induced surface reconstruction method. The combination of the BCP membrane with PET led to a new heterogeneous membrane (Fig. 11d). The system was able to respond to the changes in $\mathrm{pH}$ and temperature simultaneously, and showed excellent stability and controllability (Fig. 11e, f). The hybrid system will greatly help the development of biosensing, water purification and sustainable power generation. In addition to the dual-response nanochannels, Zheng et al. [109] modified poly[2-(dimethylamino) ethyl methacrylate]-co-[4-vinyl phenylboronic acid] (P(DMAEMA-co-VPBA)) on the wall of a single glass tapered nanochannel to demonstrate a triple-responsive nanofluidic diode. The functional groups of the copolymer brush are sensitive to $\mathrm{pH}$, temperature, and sugar, causing changes in the charge and configuration of the copolymer. As a consequence, these changes would affect the properties of the pore wall, which leads to the triple response under the experimental condition.

\section{Energy conversion}

\section{Salinity gradient energy conversion}

Salinity gradient energy, the Gibbs free energy [204] in the salt solutions of varying concentrations, is known as the blue energy and can be converted into electrical energy by reverse electrodialysis (RED) [205,206]. Considering the great potential of marine resources, the
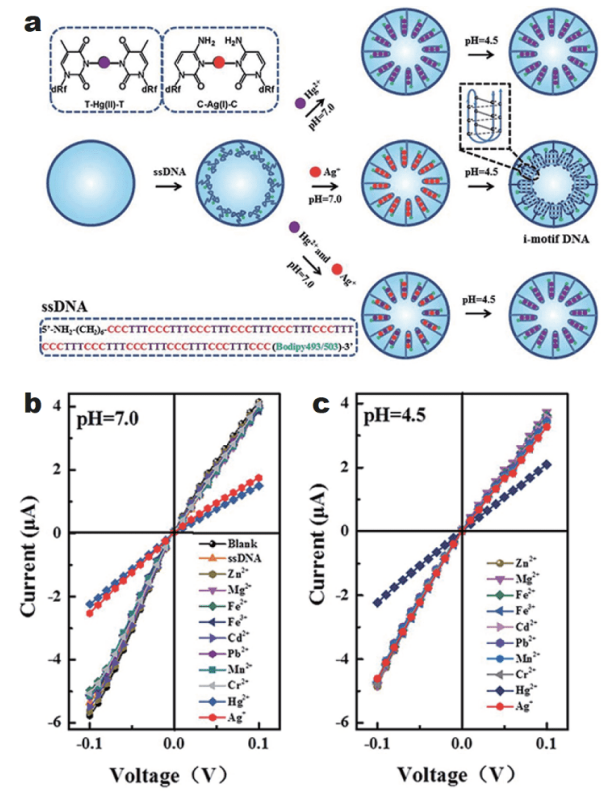

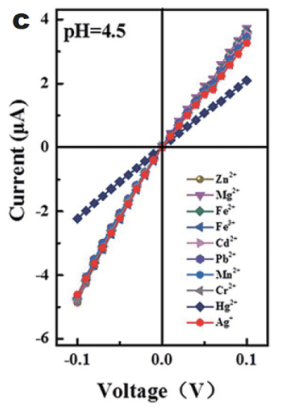

d
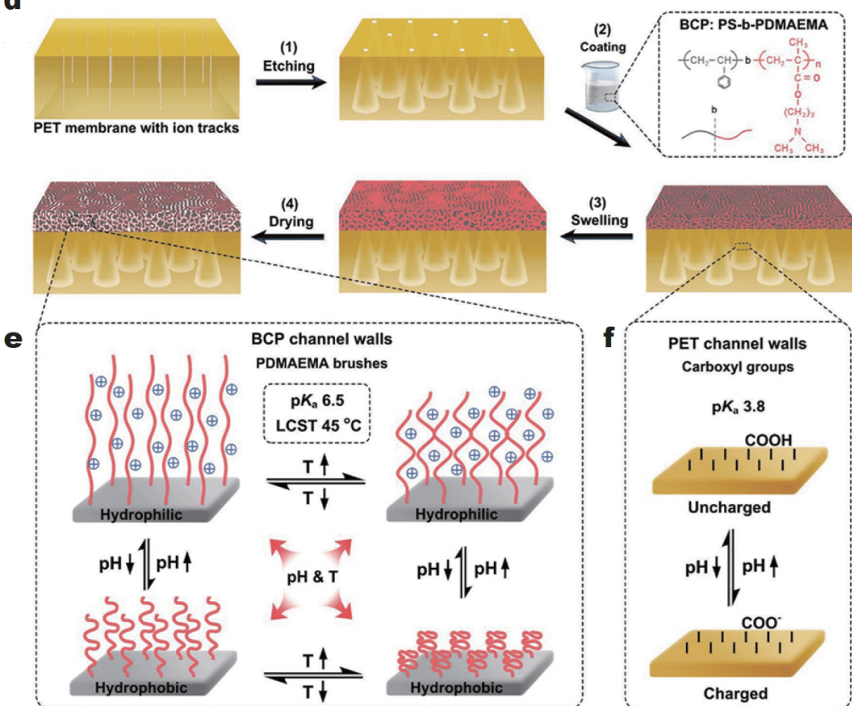

BCP channel walls BCP channel walls
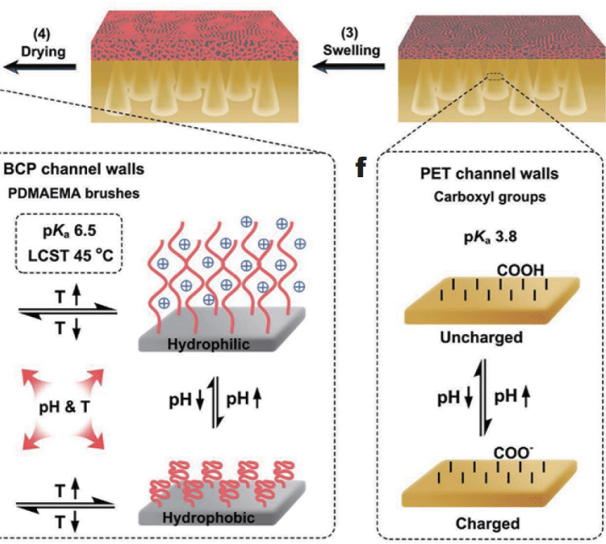

Figure 11 (a) Schematic illustration of $\mathrm{Hg}^{2+}$ and $\mathrm{Ag}^{+}$ions-responsive nanochannels. $I-V$ curves of ssDNA-modified AAO nanochannels in complex ion solutions at pH 7.0 (b) and 4.5 (c). Reprinted with permission from Ref. [20], Copyright 2015, Royal Society of Chemistry. (d) The fabrication process of the PET and polystyrene-b-PDMAEMA-based asymmetric membrane. (e) Schematic diagram of charge, wettability, and spatial configuration changes of PDMAEMA brushes under different $\mathrm{pH}$ and temperature environments. (f) The carboxylic groups on the inner walls of the PET nanochannels are also pH sensitive. Reprinted with permission from Ref. [93], Copyright 2016, WILEY-VCH Verlag GmbH \& Co. KGaA, Weinheim. 
salinity gradient has great potential in alleviating the energy crisis in the future. By regulating the migration of monopolar ions inside their confined spaces, the solidstate nanochannels $[123,207,208]$ can realize energy conversion [3,209].

Guo et al. [117] demonstrated the harvesting of salinity gradient-driven energy for the first time on a completely abiotic single-channel nanofluidic system. They pointed out two distinct advantages for the use of a single nanopore system. The first advantage is to research the influence of pore size on power generation performance by regulating and characterizing the geometry of the nanochannel, which is crucial to confirm the appropriate pore size for power generation $[54,78,210,211]$. The other advantage is achieving a stable current output throughout the measurement process. The experiment systematically measured the dependences of the zero-volt current $\left(I_{0}\right)$ and the reversal potential $\left(V_{\text {rev }}\right)$ on the concentration gradient, surface charge density and pore size. In addition, the collected power from the nanopore system was used as output for the external circuit in the experiment. The experimental results indicated that individual nanopores reached the maximum power output $\left(\left(P_{\mathrm{L}}\right)_{\max }\right)$ of $\sim 26 \mathrm{pW}$. Zhang et al. [87] also obtained considerable energy output via $\mathrm{BCP}$, which can be attributed to the elimination of the concentration polarization by using asymmetric bipolar structure and excellent anion selectivity. The harvested power from the experiment was transferred to an external circuit, which yielded a maximum output as high as $0.35 \mathrm{~W} \mathrm{~m}^{-2}$ for the heterogeneous membrane and exceeded the power efficiency generated by some commercially available cation exchange membranes [212].

Huang et al. [213] employed a phase separation method to construct a polyether sulfone/sulfonated polyether sulfone (PES/SPES) membrane with large nanochannels and applied it for the salinity gradient power generation. Meanwhile, the authors also discussed the effects of SPES content, thickness and polymer concentration on the surface structure and charge density of the PES/SPES membranes, which determines the ionic conductance and ionic selectivity of the membrane (Fig. 12). The experimental results showed maximum output power density of the PES/SPES film to be about $2.48 \mathrm{~W} \mathrm{~m}^{-2}$ in presence of 500 -fold salinity gradient $(\mathrm{NaCl}$ solution). In addition, the cost of PES/SPES membranes was about $6.2 \mathrm{USD} \mathrm{m}^{-2}$, which is lower than the commercial cost target $\left(11 \mathrm{USD} \mathrm{m}^{-2}\right.$ ) of the ion exchange membranes based on RED [214]. The improved mechanical properties of the PES/SPES membrane, and simpler membrane prepara- tion process, provide the possibility of large-scale industrial production of salinity gradient power [215].

Hsu et al. [205] further broadened the scope of research, focusing on the shape of the channel and the influence of external experimental conditions on energy harvesting, which provided an experimental and theoretical basis for further improvement of the energy collection efficiency. The $\mathrm{pH}$-adjusted nanochannels were selected by the authors for evaluation of the power generated by Gibbs free energy mixed by RED, concentrating on the effects of bulk salt concentration, the non-uniform distribution of $\mathrm{H}^{+}$, along with the size and shape of the nanochannels. And the article mentions that, the details of the convection transport of ions are considered which have been neglected by the scientific researchers in the past. For this reason, the authors also compared three different shapes of the nanochannels (bullet-shaped, conical and trumpet-shaped nanochannels). The results showed that the trumpet-shaped nanochannel has the best ion selectivity in comparison with the other two shapes. This is because the smaller the nanochannel space, the more pronounced the overlap of the EDL; for the bullet-shaped nanochannel, the maximum generated power had a local maximum due to the change in the ratio of nanochannel length/radius of curvature. Long et al. [216] studied the role of asymmetric temperature and its dependency in nanofluid-based power generation. A difference in negative temperature could considerably augment the potential of the membrane and also greatly enhance the power. Furthermore, a difference in positive temperature could obstruct the power at great intensities of transmembrane concentration and improve the power at low intensities of transmembrane concentration. The result indicated the significance of the temperature that has been ignored for decades in harvesting nanofluid energy, and supplied the manufacturing and optimization of high-performing power devices.

\section{Photoelectric conversion}

The bio-light driven ion pump uses the concentration gradient of ions to create a membrane potential [23], and converts the energy stored in sunlight into an osmotic potential. The application of nanochannels to participate in the photoelectric conversion process, directly or indirectly, has received increasing attention $[24,79,217,218]$. Wen et al. [219] introduced amino $\left(-\mathrm{NH}_{2}\right)$-terminated groups (EDA) onto the inner surface of PET to prepare a functionalized nanochannel membrane, showing the typical response characteristics of photoelectric conversion measured in presence of radiation and darkness. The 

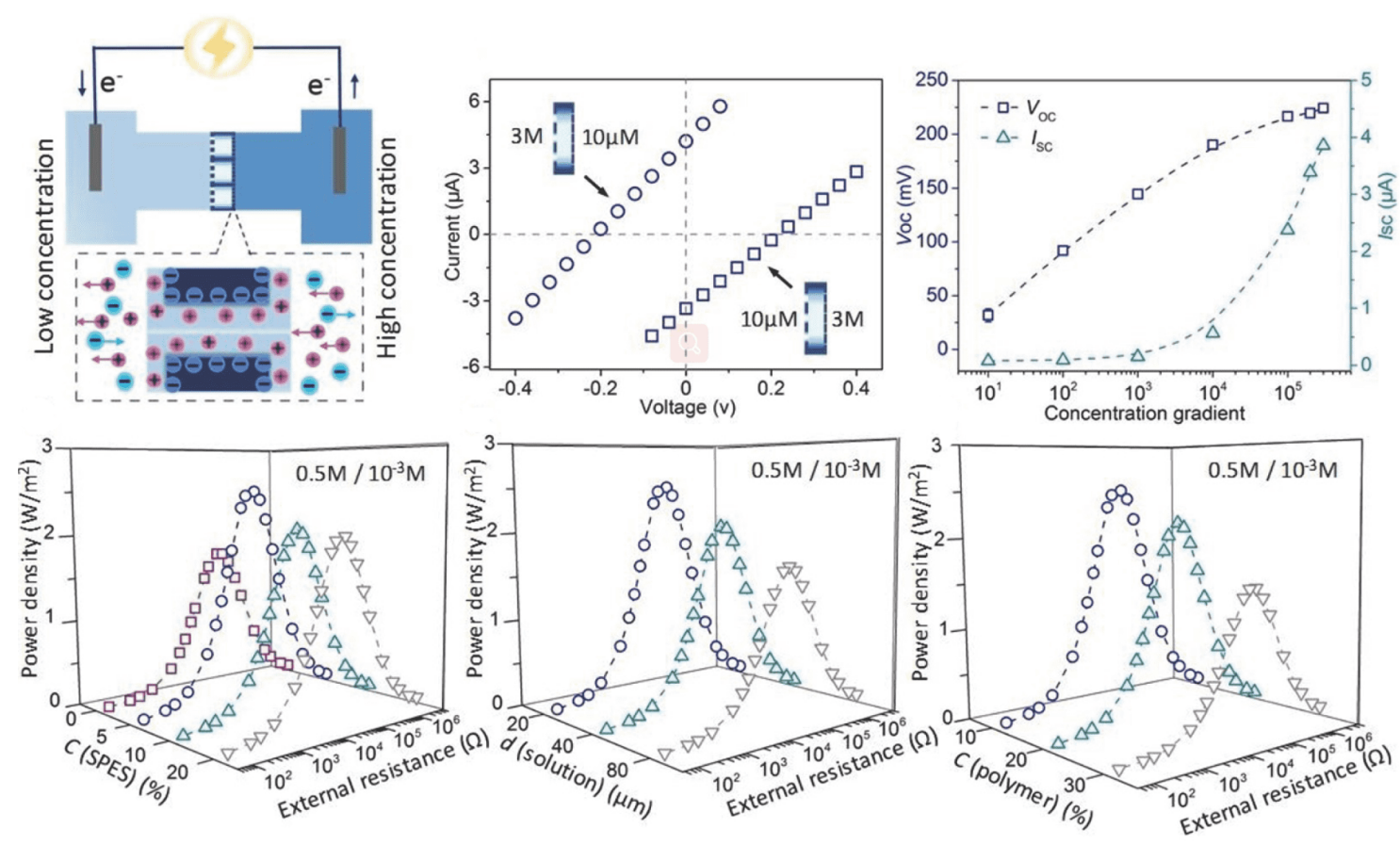

Figure 12 Salinity gradient power generation property of PES/SPES nanochannel membrane. Reprinted with permission from Ref. [213], Copyright 2019, Elsevier Ltd.

study found that when the system was in the dark, the diffusion potential $\left(E_{\mathrm{dif}}\right)$ and electrons $\left(I_{\mathrm{p}}\right)$ tended to be constant. But under radiation, immediate photochemical reaction occurred which resulted in change of $E_{\text {dif }}$ and $I_{\mathrm{p}}$. When the light was removed, both $E_{\mathrm{dif}}$ and $I_{\mathrm{p}}$ fell rapidly, and they could not be restored to their original state, showing a significant drop in the peak value when the cycle test was carried out. Further, the authors used photoelectric conversion technology and Gibbs free energy diffusion technology to calculate the conversion performance of the energy conversion system and found them to be $0.00825 \%$ and $36 \%$, respectively.

Unlike previous research, Meng et al. [79] used PSII complexes extracted from green plants and certain bacteria, the natural photoelectric conversion materials, as a "pump" to convert light into ion current (Fig. 13a). Furthermore, the authors introduced a PET film with a tapered nanochannel array into the photoelectric conversion system to adjust the light-induced ion current. It shows that the photocurrent generated by the system remains stable under radiation. The current was found to fluctuate violently and behave irregularly when the porous membrane was removed from the system, indicating that the PET nanochannel array can directly adjust the ion migration (Fig. 13b).

\section{Electrokinetic energy conversion}

Electrodynamic effect implies the situation that external pressure drives the electrolyte solution through the nanochannel with net charges and the charge separation of anion and cation occurs in the double electric layer $[220,221]$. Further, the asymmetric transport of anion and cation occurs in the channel, and subsequently the dynamic current and voltage will be generated [222]. When the current passes through an external load resistor within the fluid system, energy can be accumulated. Thus, the system of the nanochannel energy conversion found on the electrodynamic effect is capable of providing a novel choice for the conversion of fluid mechanical energy to electrical energy. In 1970s, the concept of energy conversion system based on the electrodynamic effect was proposed by Osterle's, Burgreen's and Nakache's groups [223-226]. It was expected that new findings pave the way for the energy conversion system of micro/nano fluid devices based on the electrodynamic effect more and more [227]. However, numerous investigations have indicated that the efficiency of actual energy conversion related to the conversion system based on the electrodynamic effect is relatively low and this issue has restricted its application as power devices and so on $[228,229]$. The future of energy issue in this field, directly 
a

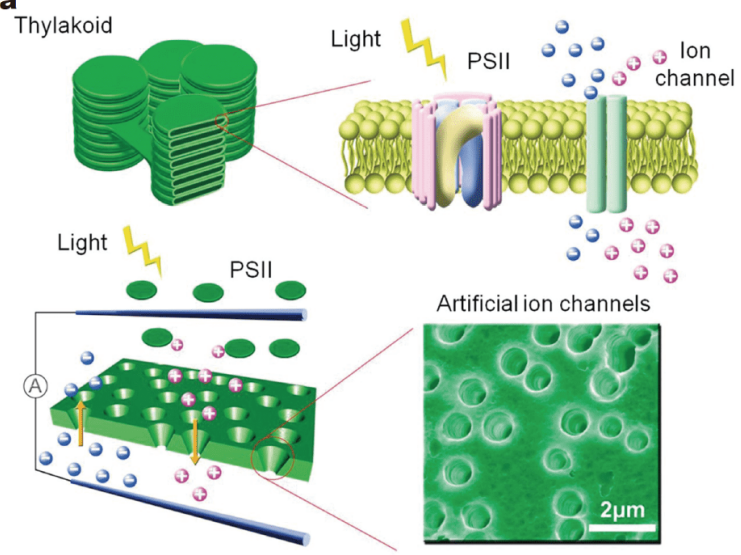

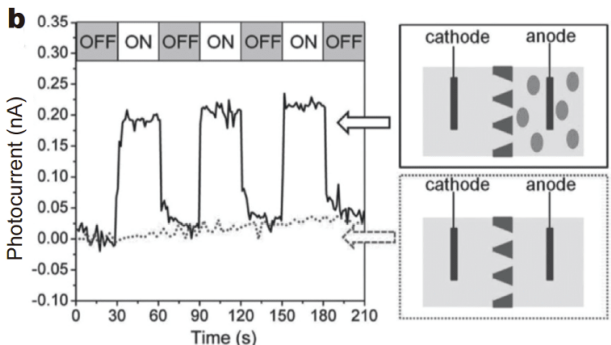

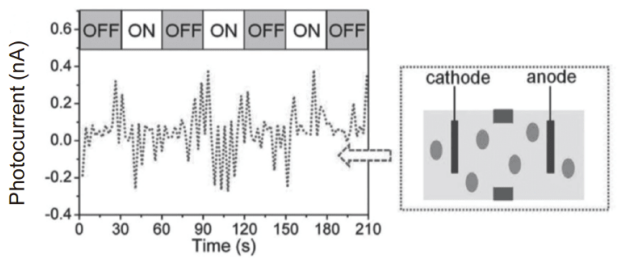

Figure 13 (a) Light-induced artificial ion channels prepared by using the PSII compound extracted from green plants and certain bacteria (natural photoelectric conversion materials) as a "pump". (b) The photocurrent of the PECS in cyclic "ON-OFF" illumination. Reprinted with permission from Ref. [79], Copyright 2013, WILEY-VCH Verlag GmbH \& Co. KGaA, Weinheim.

depends on the study of the meticulous structure optimization of nanofluid mechanics, surface chemical modification, interface slip and other surveys attributed to the construction of a fluid transport accurate control of the core of the essential circumstances which led to the break through the traditional solid-liquid interface under the limit of the bottleneck of low conversion efficiency and power output $[230,231]$.

\section{CONCLUSION}

Polymer materials play an important role in the development of bioinspired nanochannels for their unique advantages (e.g., variety, controlled structure, active surface groups). This review summarizes several preparation methods of nanochannels based on polymers, such as track-etching, self-assembly, and cross-linking, including the preparation process, design of functional groups, and schemes of novelty nanochannels. Practical applications of polymer nanochannels in biochemical sensing and energy conversion are illustrated. These applications are based on the basic properties of bioinspired nanochannels including ionic selectivity, ionic gating and ionic rectification, which are related to their particular chemical and physical structures. We hope this review will provide overall information for the scientific community on the research of bioinspired nanochannels based on polymer.

Although the research of bioinspired nanochannels has made significant progress and breakthroughs in recent years, there are still great challenges in theory and practice. We still lack the theoretical basis and models to explain the ion transport mechanism in the channel and understanding of the complex ion and molecular transport behavior, which obviously has guiding significance for the design of future nanofluidic devices. For instance, the distribution and density of charges in the nanospace, the modification status of the functional groups in the nanochannel and the development of new response mechanisms. In order to study these, it is essential to discover more appropriate systematic representation methods. Currently, to investigate the power density and the current change under various resistances is the most principal method to characterize the behavior of ion transportation within the nanochannel. Since the aforementioned cases are not obviously sufficient to achieve the considered objective, direct visualization and quantitative analysis of the ion transport behavior by using a visualized nanofluidic device is essential and it requires many novel assessment and control methods. Fortunately, molecular dynamic simulation has represented a plethora of valuable insights. To achieve a thorough understanding of the ion transport in nanospace status, considering a combination of various techniques, including molecular dynamics, statistics, and new concept such as quantum-confined superfluidics, is indispensable $[232,233]$. Moreover, although many different high-performance nanochannel membranes such as ultra-trace detection of ions, and high-performance energy conversion have been synthesized in the laboratory, it is estimated that the application of nanochannel membranes will encounter substantial challenges owing to the com- 
plexity of the actual environment. In practical application, limited by the stability, reversibility, and durability of nanochannels, nanochannels are rarely used in actual working environment, and the result does not meet the experimental expectations. More cross-linked polymers with designable chemical structurs are needed to be developed to solve this problem.

Received 4 September 2020; accepted 26 October 2020; published online 26 January 2021

1 Ali M, Yameen B, Neumann R, et al. Biosensing and supramolecular bioconjugation in single conical polymer nanochannels. Facile incorporation of biorecognition elements into nanoconfined geometries. J Am Chem Soc, 2008, 130: 16351-16357

2 Chun KY, Son YJ, Han CS. Highly sensitive and patchable pressure sensors mimicking ion-channel-engaged sensory organs. ACS Nano, 2016, 10: 4550-4558

3 Wen L, Tian Y, Ma J, et al. Construction of biomimetic smart nanochannels with polymer membranes and application in energy conversion systems. Phys Chem Chem Phys, 2012, 14: 40274042

4 Sui X, Zhang Z, Li C, et al. Engineered nanochannel membranes with diode-like behavior for energy conversion over a wide $\mathrm{pH}$ range. ACS Appl Mater Interfaces, 2019, 11: 23815-23821

5 Guo W, Tian Y, Jiang L. Asymmetric ion transport through ionchannel-mimetic solid-state nanopores. Acc Chem Res, 2013, 46: 2834-2846

6 Yameen B, Ali M, Neumann R, et al. Ionic transport through single solid-state nanopores controlled with thermally nanoactuated macromolecular gates. Small, 2009, 5: 1287-1291

7 Xia F, Jiang L. Bio-inspired, smart, multiscale interfacial materials. Adv Mater, 2008, 20: 2842-2858

8 Zhang H, Tian Y, Jiang L. Fundamental studies and practical applications of bio-inspired smart solid-state nanopores and nanochannels. Nano Today, 2016, 11: 61-81

9 Fu L, Zhai J. Biomimetic stimuli-responsive nanochannels and their applications. Electrophoresis, 2019, 40: 2058-2074

10 Zhang Z, Wen L, Jiang L. Bioinspired smart asymmetric nanochannel membranes. Chem Soc Rev, 2018, 47: 322-356

11 Morones-Ramírez JR. Bioinspired synthesis of optically and thermally responsive nanoporous membranes. NPG Asia Mater, 2013, 5: e52

12 Cong H, Wang J, Yu B, et al. Preparation of a highly permeable ordered porous microfiltration membrane of brominated poly(phenylene oxide) on an ice substrate by the breath figure method. Soft Matter, 2012, 8: 8835-8839

13 Kang Q, Guo W. 4-Biomimetic Smart Nanopores and Nanochannels. New York: Elsevier, 2017, 85-102

14 Hou X, Guo W, Jiang L. Biomimetic smart nanopores and nanochannels. Chem Soc Rev, 2011, 40: 2385-2401

15 Hou X. Design, Fabrication, Properties and Applications of Smart and Advanced Materials. Boca Raton: CRC Press, 2016. 230-274

16 Wendell D, Jing P, Geng J, et al. Translocation of double-stranded DNA through membrane-adapted phi29 motor protein nanopores. Nat Nanotech, 2009, 4: 765-772

17 Cong $\mathrm{H}, \mathrm{Xu} \mathrm{X}, \mathrm{Yu}$ B, et al. A smart temperature and magneticresponsive gating carbon nanotube membrane for ion and protein transportation. Sci Rep, 2016, 6: 32130
18 Geng Z, Song Q, Zhang X, et al. Mixed matrix membranes composed of $\mathrm{WS}_{2}$ nanosheets and fluorinated poly(2,6-dimethyl1,4-phenylene oxide) via Suzuki reaction for improved $\mathrm{CO}_{2}$ separation. J Membrane Sci, 2018, 565: 226-232

19 Zhan K, Li Z, Chen J, et al. Tannic acid modified single nanopore with multivalent metal ions recognition and ultra-trace level detection. Nano Today, 2020, 33: 100868

20 Wang $\mathrm{H}$, Hou S, Wang Q, et al. Dual-response for $\mathrm{Hg}^{2+}$ and $\mathrm{Ag}^{+}$ ions based on biomimetic funnel-shaped alumina nanochannels. J Mater Chem B, 2015, 3: 1699-1705

21 Zhang Q, Zhang Z, Zhou H, et al. Redox switch of ionic transport in conductive polypyrrole-engineered unipolar nanofluidic diodes. Nano Res, 2017, 10: 3715-3725

22 Zhang J, Liu N, Wei B, et al. The opposite gating behaviors of solid-state nanochannels modified with long and short polymer chains. Chem Commun, 2015, 51: 10146-10149

23 Xiao K, Chen L, Chen R, et al. Artificial light-driven ion pump for photoelectric energy conversion. Nat Commun, 2019, 10: 74

24 Xiao K, Tu B, Chen L, et al. Photo-driven ion transport for a photodetector based on an asymmetric carbon nitride nanotube membrane. Angew Chem Int Ed, 2019, 58: 12574-12579

25 Wang J, Hou J, Zhang $\mathrm{H}$, et al. Single nanochannel-aptamerbased biosensor for ultrasensitive and selective cocaine detection. ACS Appl Mater Interfaces, 2018, 10: 2033-2039

26 Pérez-Mitta G, Marmisollé WA, Albesa AG, et al. Phosphateresponsive biomimetic nanofluidic diodes regulated by polyamine-phosphate interactions: Insights into their functional behavior from theory and experiment. Small, 2018, 14: 1702131

27 Liu Q, Xiao K, Wen L, et al. Engineered ionic gates for ion conduction based on sodium and potassium activated nanochannels. J Am Chem Soc, 2015, 137: 11976-11983

28 Zhou D, Meng Z, Zhang M, et al. $\mathrm{pH}$-temperature cooperative dual-responsive nanogating device. Acta Chim Sin, 2015, 73: 716722

29 Guo W, Jiang L. Bioinspired smart nanochannels. In: Jabbari E, Kim DH, Lee LP, et al., (Eds.). Handbook of Biomimetics and Bioinspiration: 2 Electromechanical Systems. Singapore: World Scientific, 2014. 743-783

30 Xiao K, Giusto P, Wen L, et al. Nanofluidic ion transport and energy conversion through ultrathin free-standing polymeric carbon nitride membranes. Angew Chem Int Ed, 2018, 57: 10123-10126

31 Lathrop DK, Ervin EN, Barrall GA, et al. Monitoring the escape of DNA from a nanopore using an alternating current signal. J Am Chem Soc, 2010, 132: 1878-1885

32 Chen Z, Sun T, Qing G. Camp-modulated biomimetic ionic nanochannels based on a smart polymer. J Mater Chem B, 2019, 7: 3710-3715

33 Hou X, Siwy ZS, Ulbricht M. Advances in multi-scale pores and channels systems. Small, 2018, 14: 1800908

34 Li N, Yu S, Harrell CC, et al. Conical nanopore membranes. Preparation and transport properties. Anal Chem, 2004, 76: 2025-2030

35 Ali M, Schiedt B, Healy K, et al. Modifying the surface charge of single track-etched conical nanopores in polyimide. Nanotechnology, 2008, 19: 085713

36 Reber N, Kuchel A, Spohr R, et al. Transport properties of thermo-responsive ion track membranes. J Membrane Sci, 2001, 193: 49-58

37 Ali M, Yameen B, Cervera J, et al. Layer-by-layer assembly of 
polyelectrolytes into ionic current rectifying solid-state nanopores: Insights from theory and experiment. J Am Chem Soc, 2010, 132: 8338-8348

38 Hou X, Dong H, Zhu D, et al. Fabrication of stable single nanochannels with controllable ionic rectification. Small, 2010, 6: 361-365

39 Kalman EB, Sudre O, Vlassiouk I, et al. Control of ionic transport through gated single conical nanopores. Anal Bioanal Chem, 2009, 394: 413-419

40 Hou X, Liu Y, Dong $\mathrm{H}$, et al. A pH-gating ionic transport nanodevice: Asymmetric chemical modification of single nanochannels. Adv Mater, 2010, 22: 2440-2443

41 Han K, Heng L, Wen L, et al. Biomimetic heterogeneous multiple ion channels: A honeycomb structure composite film generated by breath figures. Nanoscale, 2016, 8: 12318-12323

42 Lin L, Yan J, Li J. Small-molecule triggered cascade enzymatic catalysis in hour-glass shaped nanochannel reactor for glucose monitoring. Anal Chem, 2014, 86: 10546-10551

43 Ma QL, Xia H, Zhang ST, et al. Investigation of proton-driven amine functionalized tube array as ion responsive biomimetic nanochannels. RSC Adv, 2016, 6: 12249-12255

44 Hou GL, Peng ZJ, Tian Y, et al. Applications of polymer single nanochannels in biosensors. Chin Sci Bull, 2013, 58: 1473-1482

45 Chen S, Tang Y, Zhan K, et al. Chemiresistive nanosensors with convex/concave structures. Nano Today, 2018, 20: 84-100

46 Heins EA, Siwy ZS, Baker LA, et al. Detecting single porphyrin molecules in a conically shaped synthetic nanopore. Nano Lett, 2005, 5: 1824-1829

47 Li R, Fan X, Liu Z, et al. Smart bioinspired nanochannels and their applications in energy-conversion systems. Adv Mater, 2017, 29: 1702983

48 Tian Y, Wen L, Hou X, et al. Bioinspired ion-transport properties of solid-state single nanochannels and their applications in sensing. ChemPhysChem, 2012, 13: 2455-2470

49 Wen L, Jiang L. Construction of biomimetic smart nanochannels for confined water. Natl Sci Rev, 2014, 1: 144-156

50 Daiguji H. Ion transport in nanofluidic channels. Chem Soc Rev, 2010, 39: 901-911

51 Huang X, Kong XY, Wen L, et al. Bioinspired ionic diodes: From unipolar to bipolar. Adv Funct Mater, 2018, 28: 1801079

52 Vlassiouk I, Smirnov S, Siwy Z. Ionic selectivity of single nanochannels. Nano Lett, 2008, 8: 1978-1985

53 Vlassiouk I, Siwy ZS. Nanofluidic diode. Nano Lett, 2007, 7: $552-$ 556

54 Siwy ZS. Ion-current rectification in nanopores and nanotubes with broken symmetry. Adv Funct Mater, 2006, 16: 735-746

55 Sun Z, Han C, Wen L, et al. pH gated glucose responsive biomimetic single nanochannels. Chem Commun, 2012, 48: 32823284

56 Hou X, Yang F, Li L, et al. A biomimetic asymmetric responsive single nanochannel. J Am Chem Soc, 2010, 132: 11736-11742

57 Zhang LX, Cai SL, Zheng YB, et al. Smart homopolymer modification to single glass conical nanopore channels: Dual-stimuliactuated highly efficient ion gating. Adv Funct Mater, 2011, 21: 2103-2107

58 Seifert A, Göpfrich K, Burns JR, et al. Bilayer-spanning DNA nanopores with voltage-switching between open and closed state. ACS Nano, 2015, 9: 1117-1126

59 Smirnov S, Vlassiouk I, Takmakov $\mathrm{P}$, et al. Water confinement in hydrophobic nanopores. Pressure-induced wetting and drying.
ACS Nano, 2010, 4: 5069-5075

60 Zhang $\mathrm{H}$, Hou X, Zeng L, et al. Bioinspired artificial single ion pump. J Am Chem Soc, 2013, 135: 16102-16110

61 Friebe A, Ulbricht M. Cylindrical pores responding to two different stimuli via surface-initiated atom transfer radical polymerization for synthesis of grafted diblock copolymers. Macromolecules, 2009, 42: 1838-1848

62 Qian YC, Tian W, Wen LP. The polymer-based nanochannels: Construction, functionalization and application. Polym Bull, 2019, 10: $10-20$

63 Yameen B, Ali M, Neumann R, et al. Synthetic proton-gated ion channels via single solid-state nanochannels modified with responsive polymer brushes. Nano Lett, 2009, 9: 2788-2793

64 Xiao K, Zhou Y, Kong XY, et al. Electrostatic-charge- and electric-field-induced smart gating for water transportation. ACS Nano, 2016, 10: 9703-9709

65 Xiao K, Chen L, Xie G, et al. A bio-inspired dumbbell-shaped nanochannel with a controllable structure and ionic rectification. Nanoscale, 2018, 10: 6850-6854

66 Sun $\mathrm{Y}$, Zhang $\mathrm{F}$, Sun $\mathrm{Z}$, et al. $\mathrm{Zn}^{2+}$ and EDTA cooperative switchable nanofluidic diode based on asymmetric modification of single nanochannel. Chem Eur J, 2016, 22: 4355-4358

67 Zhang H, Hou X, Yang Z, et al. Bio-inspired smart single asymmetric hourglass nanochannels for continuous shape and ion transport control. Small, 2015, 11: 786-791

68 Zhang H, Hou X, Hou J, et al. Synthetic asymmetric-shaped nanodevices with symmetric $\mathrm{pH}$-gating characteristics. Adv Funct Mater, 2015, 25: 1102-1110

69 Ali M, Ramirez P, Mafé S, et al. A pH-tunable nanofluidic diode with a broad range of rectifying properties. ACS Nano, 2009, 3: 603-608

70 Siwy Z, Apel P, Dobrev D, et al. Ion transport through asymmetric nanopores prepared by ion track etching. Nucl Instrum Methods Phys Res Sect B-Beam Interactions Mater Atoms, 2003, 208: $143-148$

71 Zhang Y, Kong XY, Gao L, et al. Fabrication of nanochannels. Materials, 2015, 8: 6277-6308

72 Trautmann C, Brüchle W, Spohr R, et al. Pore geometry of etched ion tracks in polyimide. Nucl Instruments Methods Phys Res Sect B-Beam Interactions Mater Atoms, 1996, 111: 70-74

73 Sun Z, Han C, Song M, et al. Fabrication of cysteine-responsive biomimetic single nanochannels by a thiol-yne reaction strategy and their application for sensing in urine samples. Adv Mater, 2014, 26: 455-460

74 Wen LP, Jiang L. Bio-inspired smart gating nanochannels based on polymer films. Sci China Chem, 2011, 54: 1537-1546

75 Khalid W, Akhtar J. Fabrication and Functionalization of Nanochannels for Sensing Applications. Amsterdam: Elsevier, 2020, 157-169

76 Guo Z, Wang J, Wang E. Selective discrimination of small hydrophobic biomolecules based on ion-current rectification in conically shaped nanochannel. Talanta, 2012, 89: 253-257

77 Guo Z, Wang J, Ren J, et al. pH-reversed ionic current rectification displayed by conically shaped nanochannel without any modification. Nanoscale, 2011, 3: 3767-3773

78 Wharton JE, Jin P, Sexton LT, et al. A method for reproducibly preparing synthetic nanopores for resistive-pulse biosensors. Small, 2007, 3: 1424-1430

79 Meng Z, Bao H, Wang J, et al. Artificial ion channels regulating light-induced ionic currents in photoelectrical conversion sys- 
tems. Adv Mater, 2014, 26: 2329-2334

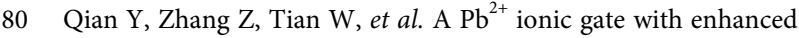
stability and improved sensitivity based on a 4'-aminobenzo-18crown-6 modified funnel-shaped nanochannel. Faraday Discuss, 2018, 210: 101-111

81 Zhang F, Ma J, Sun Y, et al. Fabrication of a mercaptoacetic acid pillar[5]arene assembled nanochannel: A biomimetic gate for mercury poisoning. Chem Sci, 2016, 7: 3227-3233

82 Gao L, Li P, Zhang Y, et al. A bio-inspired, sensitive, and selective ionic gate driven by silver (I) ions. Small, 2015, 11: 543-547

83 Li M, Xiong Y, Wang D, et al. Biomimetic nanochannels for the discrimination of sialylated glycans via a tug-of-war between glycan binding and polymer shrinkage. Chem Sci, 2020, 11: 748756

84 Xiao K, Wu K, Chen L, et al. Biomimetic peptide-gated nanoporous membrane for on-demand molecule transport. Angew Chem Int Ed, 2018, 57: 151-155

85 Zhao C, Li X, Li L, et al. Mimicking the binding and unbinding of $\mathrm{Fe}^{3+}$ with transferrin using a single biomimetic nanochannel. Chem Commun, 2013, 49: 9317-9319

86 Han C, Su H, Sun Z, et al. Biomimetic ion nanochannels as a highly selective sequential sensor for zinc ions followed by phosphate anions. Chem Eur J, 2013, 19: 9388-9395

87 Zhang Z, Kong XY, Xiao K, et al. Engineered asymmetric heterogeneous membrane: A concentration-gradient-driven energy harvesting device. J Am Chem Soc, 2015, 137: 14765-14772

88 Zhang H, Tian Y, Hou J, et al. Bioinspired smart gate-locationcontrollable single nanochannels: Experiment and theoretical simulation. ACS Nano, 2015, 9: 12264-12273

89 Yameen B, Ali M, Neumann R, et al. Proton-regulated rectified ionic transport through solid-state conical nanopores modified with phosphate-bearing polymer brushes. Chem Commun, 2010, 46: $1908-1910$

90 Wen L, Hou X, Tian Y, et al. Bio-inspired photoelectric conversion based on smart-gating nanochannels. Adv Funct Mater, 2010, 20: 2636-2642

91 Guo W, Xia H, Xia F, et al. Current rectification in temperatureresponsive single nanopores. ChemPhysChem, 2010, 11: 859-864

92 Alem H, Duwez AS, Lussis $\mathrm{P}$, et al. Microstructure and thermoresponsive behavior of poly( $N$-isopropylacrylamide) brushes grafted in nanopores of track-etched membranes. J Membrane Sci, 2008, 308: 75-86

93 Zhang Z, Xie G, Xiao K, et al. Asymmetric multifunctional heterogeneous membranes for $\mathrm{pH}$ - and temperature-cooperative smart ion transport modulation. Adv Mater, 2016, 28: 9613-9619

94 Xiao K, Xie G, Li P, et al. A biomimetic multi-stimuli-response ionic gate using a hydroxypyrene derivation-functionalized asymmetric single nanochannel. Adv Mater, 2014, 26: 6560-6565

95 Nasir S, Ali M, Ramirez P, et al. Fabrication of single cylindrical Au-coated nanopores with non-homogeneous fixed charge distribution exhibiting high current rectifications. ACS Appl Mater Interfaces, 2014, 6: 12486-12494

96 Zhao Y, Janot JM, Balanzat E, et al. Mimicking pH-gated ionic channels by polyelectrolyte complex confinement inside a single nanopore. Langmuir, 2017, 33: 3484-3490

97 Wang R, Sun Y, Zhang F, et al. Temperature-sensitive artificial channels through pillar[5] arene-based host-guest interactions. Angew Chem Int Ed, 2017, 56: 5294-5298

98 Pérez-Mitta G, Tuninetti JS, Knoll W, et al. Polydopamine meets solid-state nanopores: A bioinspired integrative surface chemistry approach to tailor the functional properties of nanofluidic diodes. J Am Chem Soc, 2015, 137: 6011-6017

99 Zhou Y, Guo W, Cheng J, et al. High-temperature gating of solidstate nanopores with thermo-responsive macromolecular nanoactuators in ionic liquids. Adv Mater, 2012, 24: 962-967

100 Meng Z, Chen Y, Li X, et al. Cooperative effect of pH-dependent ion transport within two symmetric-structured nanochannels. ACS Appl Mater Interfaces, 2015, 7: 7709-7716

101 Milne Z, Yeh LH, Chou TH, et al. Tunable Donnan potential and electrokinetic flow in a biomimetic gated nanochannel with $\mathrm{pH}$ regulated polyelectrolyte brushes. J Phys Chem C, 2014, 118: 19806-19813

102 Jung Y, Bayley H, Movileanu L. Temperature-responsive protein pores. J Am Chem Soc, 2006, 128: 15332-15340

103 Shi L, Mu C, Gao T, et al. Rhodopsin-like ionic gate fabricated with graphene oxide and isomeric DNA switch for efficient photocontrol of ion transport. J Am Chem Soc, 2019, 141: 82398243

104 Yang L, Qian Y, Kong XY, et al. Specific recognition of uranyl ion employing a functionalized nanochannel platform for dealing with radioactive contamination. ACS Appl Mater Interfaces, 2020, 12: 3854-3861

105 Wen L, Ma J, Tian Y, et al. A photo-induced, and chemicaldriven, smart-gating nanochannel. Small, 2012, 8: 838-842

106 Lu Q, Tang Q, Chen Z, et al. Developing an inositol-phosphateactuated nanochannel system by mimicking biological calcium ion channels. ACS Appl Mater Interfaces, 2017, 9: 32554-32564

107 Vlassiouk I, Park CD, Vail SA, et al. Control of nanopore wetting by a photochromic spiropyran: A light-controlled valve and electrical switch. Nano Lett, 2006, 6: 1013-1017

108 Liu NG, Dunphy DR, Atanassov P, et al. Photoregulation of mass transport through a photoresponsive azobenzene-modified nanoporous membrane. Nano Lett, 2004, 4: 551-554

109 Zheng YB, Zhao S, Cao SH, et al. A temperature, $\mathrm{pH}$ and sugar triple-stimuli-responsive nanofluidic diode. Nanoscale, 2017, 9: 433-439

110 Kong J, Mu Y, Xiong Y, et al. Fabrication of both $\mathrm{TiO}_{2}$ nanostructures and cysteine-modified AAO membranes and their application in chiral selective transport of proteins. J Elec Mater, 2019, 48: 964-971

111 Liao T, Li X, Tong Q, et al. Ultrasensitive detection of micrornas with morpholino-functionalized nanochannel biosensor. Anal Chem, 2017, 89: 5511-5518

112 Zhu F, Yang G, Dhinakaran MK, et al. A pyrophosphate-activated nanochannel inspired by a trp ion channel. Chem Commun, 2019, 55: 12833-12836

113 Liu P, Xie G, Li P, et al. A universal tunable nanofluidic diode via photoresponsive host-guest interactions. NPG Asia Mater, 2018, 10: 849-857

114 Shang X, Xie G, Kong XY, et al. An artificial $\mathrm{CO}_{2}$-driven ionic gate inspired by olfactory sensory neurons in mosquitoes. Adv Mater, 2017, 29: 1603884

115 Siwy Z, Dobrev D, Neumann R, et al. Electro-responsive asymmetric nanopores in polyimide with stable ion-current signal. Appl Phys A-Mater Sci Processing, 2003, 76: 781-785

116 Xie G, Tian W, Wen L, et al. Chiral recognition of $L$-tryptophan with beta-cyclodextrin-modified biomimetic single nanochannel. Chem Commun, 2015, 51: 3135-3138

117 Guo W, Cao L, Xia J, et al. Energy harvesting with single-ionselective nanopores: A concentration-gradient-driven nanofluidic 
power source. Adv Funct Mater, 2010, 20: 1339-1344

118 Deng M, Yang M, Xu Y, et al. Biomimetic nanochannel membrane for cascade response of borate and cis-hydroxyl compounds: An IMP logic gate device. Chin Chem Lett, 2019, 30: 1397-1400

119 Lokuge I, Wang X, Bohn PW. Temperature-controlled flow switching in nanocapillary array membranes mediated by poly $(\mathrm{N}$ isopropylacrylamide) polymer brushes grafted by atom transfer radical polymerization. Langmuir, 2007, 23: 305-311

120 Zhu X, Hao J, Bao B, et al. Unique ion rectification in hypersaline environment: A high-performance and sustainable power generator system. Sci Adv, 2018, 4: 1665

121 Zhang Z, Huang X, Qian Y, et al. Engineering smart nanofluidic systems for artificial ion channels and ion pumps: From singlepore to multichannel membranes. Adv Mater, 2020, 32: 1904351

122 Zhao Y, Wang J, Kong XY, et al. Robust sulfonated poly (ether ether ketone) nanochannels for high-performance osmotic energy conversion. Natl Sci Rev, 2020, 7: 1349-1359

123 Xin W, Zhang Z, Huang X, et al. High-performance silk-based hybrid membranes employed for osmotic energy conversion. Nat Commun, 2019, 10: 3876

124 Chen J, Xin W, Kong XY, et al. Ultrathin and robust silk fibroin membrane for high-performance osmotic energy conversion. ACS Energy Lett, 2019, 5: 742-748

125 Yohe ST, Freedman JD, Falde EJ, et al. A mechanistic study of wetting superhydrophobic porous 3D meshes. Adv Funct Mater, 2013, 23: 3628-3637

126 Zhang Z, He L, Zhu C, et al. Improved osmotic energy conversion in heterogeneous membrane boosted by three-dimensional hydrogel interface. Nat Commun, 2020, 11: 875

127 Zhang W, Zhao Q, Yuan J. Porous polyelectrolytes: The interplay of charge and pores for new functionalities. Angew Chem Int Ed, 2018, 57: 6754-6773

128 Zhu Y, Zhan K, Hou X. Interface design of nanochannels for energy utilization. ACS Nano, 2018, 12: 908-911

129 Chen W, Wang Q, Chen J, et al. Improved ion transport and high energy conversion through hydrogel membrane with $3 \mathrm{D}$ interconnected nanopores. Nano Lett, 2020, 20: 5705-5713

130 Schroeder TBH, Guha A, Lamoureux A, et al. An electric-eelinspired soft power source from stacked hydrogels. Nature, 2017, 552: 214-218

131 Xiao K, Wen L, Jiang L. Biomimetic solid-state nanochannels: From fundamental research to practical applications. Small, 2016, 12: $2810-2831$

132 Dorin RM, Phillip WA, Sai H, et al. Designing block copolymer architectures for targeted membrane performance. Polymer, 2014, 55: 347-353

133 Robbins SW, Beaucage PA, Sai H, et al. Block copolymer selfassembly-directed synthesis of mesoporous gyroidal superconductors. Sci Adv, 2016, 2: e1501119

134 Zhang Z, Kong XY, Xiao K, et al. A bioinspired multifunctional heterogeneous membrane with ultrahigh ionic rectification and highly efficient selective ionic gating. Adv Mater, 2016, 28: 144150

$135 \mathrm{Gu}$ X, Gunkel I, Hexemer A, et al. Controlling domain spacing and grain size in cylindrical block copolymer thin films by means of thermal and solvent vapor annealing. Macromolecules, 2016, 49: 3373-3381

136 Yu H, Qiu X, Moreno N, et al. Self-assembled asymmetric block copolymer membranes: Bridging the gap from ultra- to nanofil- tration. Angew Chem Int Ed, 2015, 54: 13937-13941

137 Ahn H, Park S, Kim SW, et al. Nanoporous block copolymer membranes for ultrafiltration: A simple approach to size tunability. ACS Nano, 2014, 8: 11745-11752

138 Dorin RM, Sai H, Wiesner U. Hierarchically porous materials from block copolymers. Chem Mater, 2013, 26: 339-347

139 Zhang Z, Sui X, Li P, et al. Ultrathin and ion-selective Janus membranes for high-performance osmotic energy conversion. J Am Chem Soc, 2017, 139: 8905-8914

140 Qiu X, Yu H, Karunakaran M, et al. Selective separation of similarly sized proteins with tunable nanoporous block copolymer membranes. ACS Nano, 2013, 7: 768-776

141 Sui X, Zhang Z, Zhang Z, et al. Biomimetic nanofluidic diode composed of dual amphoteric channels maintains rectification direction over a wide $\mathrm{pH}$ range. Angew Chem Int Ed, 2016, 55: 13056-13060

142 Feng Y, Zhu W, Guo W, et al. Bioinspired energy conversion in nanofluidics: A paradigm of material evolution. Adv Mater, 2017, 29: 1702773

143 Laucirica G, Toimil-Molares ME, Trautmann C, et al. Polyaniline for improved blue energy harvesting: Highly rectifying nanofluidic diodes operating in hypersaline conditions via one-step functionalization. ACS Appl Mater Interfaces, 2020, 12: 2814828157

144 Hou X, Zhang H, Jiang L. Building bio-inspired artificial functional nanochannels: From symmetric to asymmetric modification. Angew Chem Int Ed, 2012, 51: 5296-5307

145 Hou X. Smart gating multi-scale pore/channel-based membranes. Adv Mater, 2016, 28: 7049-7064

146 Harrell CC, Kohli P, Siwy Z, et al. DNA-nanotube artificial ion channels. J Am Chem Soc, 2004, 126: 15646-15647

147 Hou X, Guo W, Xia F, et al. A biomimetic potassium responsive nanochannel: G-quadruplex DNA conformational switching in a synthetic nanopore. J Am Chem Soc, 2009, 131: 7800-7805

148 Sharma MK, Agarwal R. In situ electrochemical impedance spectroscopy to monitor oxidative polymerization of aniline by $\mathrm{HAuCl}_{4}$ in nanochannels of track-etched membrane. ChemistrySelect, 2016, 1: 5062-5065

149 Ali M, Schiedt B, Neumann R, et al. Biosensing with functionalized single asymmetric polymer nanochannels. Macromol Biosci, 2010, 10: 28-32

150 Yu B, Song Q, Cong H, et al. A smart thermo- and $\mathrm{pH}$-responsive microfiltration membrane based on three-dimensional inverse colloidal crystals. Sci Rep, 2017, 7: 12112

151 Zhang H, Tian Y, Jiang L. From symmetric to asymmetric design of bio-inspired smart single nanochannels. Chem Commun, 2013, 49: 10048-10063

152 Nunes SP, Behzad AR, Hooghan B, et al. Switchable pH-responsive polymeric membranes prepared via block copolymer micelle assembly. ACS Nano, 2011, 5: 3516-3522

153 Wen L, Xiao K, Sainath AVS, et al. Engineered asymmetric composite membranes with rectifying properties. Adv Mater, 2016, 28: 757-763

154 Tagliazucchi M, Azzaroni O, Szleifer I. Responsive polymers endtethered in solid-state nanochannels: When nanoconfinement really matters. J Am Chem Soc, 2010, 132: 12404-12411

155 Lindqvist J, Nystrom D, Ostmark E, et al. Intelligent dual-responsive cellulose surfaces via surface-initiated ATRP. Biomacromolecules, 2008, 9: 2139-2145

156 Cheng LJ, Guo LJ. Ionic current rectification, breakdown, and 
switching in heterogeneous oxide nanofluidic devices. ACS Nano, 2009, 3: 575-584

157 Xiao K, Kong XY, Zhang Z, et al. Construction and application of photoresponsive smart nanochannels. J Photochem Photobiol CPhotochem Rev, 2016, 26: 31-47

158 Banghart $\mathrm{M}$, Borges $\mathrm{K}$, Isacoff $\mathrm{E}$, et al. Light-activated ion channels for remote control of neuronal firing. Nat Neurosci, 2004, 7: 1381-1386

159 Hoersch D, Roh SH, Chiu W, et al. Reprogramming an ATPdriven protein machine into a light-gated nanocage. Nat Nanotech, 2013, 8: 928-932

160 Wang G, Bohaty AK, Zharov I, et al. Photon gated transport at the glass nanopore electrode. J Am Chem Soc, 2006, 128: 1355313558

161 Sun Y, Ma J, Zhang F, et al. A light-regulated host-guest-based nanochannel system inspired by channelrhodopsins protein. Nat Commun, 2017, 8: 260

162 Li P, Xie G, Kong XY, et al. Light-controlled ion transport through biomimetic DNA-based channels. Angew Chem Int Ed, 2016, 55: 15637-15641

$163 \mathrm{Hu}$ Y, Guo W, Kahn JS, et al. A shape-memory DNA-based hydrogel exhibiting two internal memories. Angew Chem Int Ed, 2016, 55: 4210-4214

164 You M, Chen Y, Zhang X, et al. An autonomous and controllable light-driven DNA walking device. Angew Chem Int Ed, 2012, 51: 2457-2460

165 Kumar BVVSP, Sonu KP, Rao KV, et al. Supramolecular switching of ion-transport in nanochannels. ACS Appl Mater Interfaces, 2018, 10: 23458-23465

166 Kumar BVVSP, Rao KV, Sampath S, et al. Supramolecular gating of ion transport in nanochannels. Angew Chem Int Ed, 2014, 53: 13073-13077

167 Wu K, Xiao K, Chen L, et al. Biomimetic voltage-gated ultrasensitive potassium-activated nanofluidic based on a solid-state nanochannel. Langmuir, 2017, 33: 8463-8467

168 Zhang Y, Zhou R, Zhao Z, et al. Sequential recognition of zinc and pyrophosphate ions in a terpyridine-functionalized single nanochannel. ChemPhysChem, 2017, 18: 253-259

169 Tian Y, Hou X, Wen L, et al. A biomimetic zinc activated ion channel. Chem Commun, 2010, 46: 1682-1684

$170 \mathrm{Xu} \mathrm{Y,} \mathrm{Meng} \mathrm{Z,} \mathrm{Zhai} \mathrm{J.} \mathrm{pH}$ and calcium cooperative regulation nanofluidic gating device. Acta Chim Sin, 2016, 74: 538-544

171 Liu Q, Wen L, Xiao K, et al. A biomimetic voltage-gated chloride nanochannel. Adv Mater, 2016, 28: 3181-3186

172 Lee JH, Wang Z, Liu J, et al. Highly sensitive and selective colorimetric sensors for uranyl $\left(\mathrm{UO}_{2}^{2+}\right)$ : Development and comparison of labeled and label-free DNAzyme-gold nanoparticle systems. J Am Chem Soc, 2008, 130: 14217-14226

$173 \mathrm{Xu} \mathrm{HQ}, \mathrm{Hu} J$, Wang D, et al. Visible-light photoreduction of $\mathrm{CO}_{2}$ in a metal-organic framework: Boosting electron-hole separation via electron trap states. J Am Chem Soc, 2015, 137: 13440-13443

174 Jiang Z, Zhang Y, Liang A, et al. Free-labeled nanogold catalytic detection of trace $\mathrm{UO}_{2}{ }^{2+}$ based on the aptamer reaction and gold particle resonance scattering effect. Plasmonics, 2012, 7: 185-190

175 Cao XH, Zhang HY, Ma RC, et al. Visual colorimetric detection of $\mathrm{UO}_{2}{ }^{2+}$ using $o$-phosphorylethanolamine-functionalized gold nanoparticles. Sens Actuat B-Chem, 2015, 218: 67-72

176 Gao HL, Wang M, Wu ZQ, et al. Morpholino-functionalized nanochannel array for label-free single nucleotide polymorphisms detection. Anal Chem, 2015, 87: 3936-3941
177 Li SJ, Xia N, Yuan BQ, et al. A novel DNA sensor using a sandwich format by electrochemical measurement of marker ion fluxes across nanoporous alumina membrane. Electrochim Acta, 2015, 159: 234-241

178 Wang X, Smirnov S. Label-free DNA sensor based on surface charge modulated ionic conductance. ACS Nano, 2009, 3: 10041010

179 Li CY, Tian YW, Shao WT, et al. Solution $\mathrm{pH}$ regulating mass transport in highly ordered nanopore array electrode. Electrochem Commun, 2014, 42: 1-5

180 de la Escosura-Muñiz A, Chunglok W, Surareungchai W, et al. Nanochannels for diagnostic of thrombin-related diseases in human blood. Biosens Bioelectron, 2013, 40: 24-31

181 de la Escosura-Muñiz A, Merkoçi A. A nanochannel/nanoparticle-based filtering and sensing platform for direct detection of a cancer biomarker in blood. Small, 2011, 7: 675-682

182 Long Z, Zhan S, Gao P, et al. Recent advances in solid nanopore/ channel analysis. Anal Chem, 2018, 90: 577-588

183 Chen ZM, Shen GZ, Li YP, et al. A novel biomimetic logic gate for sensitive and selective detection of $\mathrm{Pb}(\mathrm{II})$ base on porous alumina nanochannels. Electrochem Commun, 2015, 60: 83-87

184 Ueki T, Arai AA, Kodama K, et al. Thermodynamic study on phase transitions of poly(benzyl methacrylate) in ionic liquid solvents. Pure Appl Chem, 2009, 81: 1829-1841

185 Pérez-Mitta G, Albesa AG, Trautmann C, et al. Bioinspired integrated nanosystems based on solid-state nanopores: "Iontronic" transduction of biological, chemical and physical stimuli. Chem Sci, 2017, 8: 890-913

186 Guo W, Xia $\mathrm{H}$, Cao L, et al. Integrating ionic gate and rectifier within one solid-state nanopore via modification with dual-responsive copolymer brushes. Adv Funct Mater, 2010, 20: 35613567

187 Liu N, Jiang Y, Zhou Y, et al. Two-way nanopore sensing of sequence-specific oligonucleotides and small-molecule targets in complex matrices using integrated DNA supersandwich structures. Angew Chem Int Ed, 2013, 52: 2007-2011

188 Zhang $\mathrm{M}$, Hou $\mathrm{X}$, Wang $\mathrm{J}$, et al. Light and $\mathrm{pH}$ cooperative nanofluidic diode using a spiropyran-functionalized single nanochannel. Adv Mater, 2012, 24: 2424-2428

189 Ali M, Nasir S, Nguyen QH, et al. Metal ion affinity-based biomolecular recognition and conjugation inside synthetic polymer nanopores modified with iron-terpyridine complexes. J Am Chem Soc, 2011, 133: 17307-17314

190 Han C, Hou X, Zhang H, et al. Enantioselective recognition in biomimetic single artificial nanochannels. J Am Chem Soc, 2011, 133: 7644-7647

191 Asatekin A, Gleason KK. Polymeric nanopore membranes for hydrophobicity-based separations by conformal initiated chemical vapor deposition. Nano Lett, 2011, 11: 677-686

192 Ma Q, Si Z, Li Y, et al. Functional solid-state nanochannels for biochemical sensing. TrAC Trends Anal Chem, 2019, 115: 174186

193 Aliofkhazraei M. Handbook of Nanoparticles. Cham: Springer, 2016

194 Aznar E, Oroval M, Pascual L, et al. Gated materials for oncommand release of guest molecules. Chem Rev, 2016, 116: 561718

195 Lee JH, Chen KJ, Noh SH, et al. On-demand drug release system for in vivo cancer treatment through self-assembled magnetic nanoparticles. Angew Chem Int Ed, 2013, 52: 4384-4388 
Zhu Z, Wang D, Tian Y, et al. Ion/molecule transportation in nanopores and nanochannels: From critical principles to diverse functions. J Am Chem Soc, 2019, 141: 8658-8669

197 Deamer D, Akeson M, Branton D. Three decades of nanopore sequencing. Nat Biotechnol, 2016, 34: 518-524

198 Siwy ZS, Davenport M. Making nanopores from nanotubes. Nat Nanotech, 2010, 5: 174-175

199 Griffiths J. The realm of the nanopore. Anal Chem, 2008, 80: 23 27

200 Gao P, Martin CR. Voltage charging enhances ionic conductivity in gold nanotube membranes. ACS Nano, 2014, 8: 8266-8272

201 Yusko EC, Bruhn BR, Eggenberger OM, et al. Real-time shape approximation and fingerprinting of single proteins using a nanopore. Nat Nanotech, 2017, 12: 360-367

202 Masuda H, Fukuda K. Ordered metal nanohole arrays made by a two-step replication of honeycomb structures of anodic alumina. Science, 1995, 268: 1466-1468

203 Zoppe JO, Ataman NC, Mocny P, et al. Surface-initiated controlled radical polymerization: State-of-the-art, opportunities, and challenges in surface and interface engineering with polymer brushes. Chem Rev, 2017, 117: 1105-1318

204 Hsu JP, Su TC, Peng PH, et al. Unraveling the anomalous surfacecharge-dependent osmotic power using a single funnel-shaped nanochannel. ACS Nano, 2019, 13: 13374-13381

205 Hsu JP, Su TC, Lin CY, et al. Power generation from a pHregulated nanochannel through reverse electrodialysis: Effects of nanochannel shape and non-uniform $\mathrm{H}^{+}$distribution. Electrochim Acta, 2019, 294: 84-92

206 Hong S, Zou G, Kim H, et al. Photothermoelectric response of $\mathrm{Ti}_{3} \mathrm{C}_{2} \mathrm{~T}_{x}$ MXene confined ion channels. ACS Nano, 2020, 14: 9042-9049

207 Hwang J, Kataoka S, Endo A, et al. Enhanced energy harvesting by concentration gradient-driven ion transport in SBA-15 mesoporous silica thin films. Lab Chip, 2016, 16: 3824-3832

208 Cao L, Guo W, Ma W, et al. Towards understanding the nanofluidic reverse electrodialysis system: Well matched charge selectivity and ionic composition. Energy Environ Sci, 2011, 4: 2259-2266

209 Yan F, Yao L, Chen K, et al. An ultrathin and highly porous silica nanochannel membrane: Toward highly efficient salinity energy conversion. J Mater Chem A, 2019, 7: 2385-2391

210 Lemay SG. Nanopore-based biosensors: The interface between ionics and electronics. ACS Nano, 2009, 3: 775-779

211 Zhang Y, Huang Z, He Y, et al. Enhancing the efficiency of energy harvesting from salt gradient with ion-selective nanochannel. Nanotechnology, 2019, 30: 295402

212 Veerman J, Saakes M, Metz SJ, et al. Reverse electrodialysis: Performance of a stack with 50 cells on the mixing of sea and river water. J Membrane Sci, 2009, 327: 136-144

213 Huang X, Zhang Z, Kong XY, et al. Engineered PES/SPES nanochannel membrane for salinity gradient power generation. Nano Energy, 2019, 59: 354-362

214 Vanoppen M, Blandin G, Derese S, et al. Salinity gradient power and desalination. In: Cipollina A, Micale G (Eds.). Sustainable Energy from Salinity Gradients. Cambridge: Elsevier, 2016. 281313

215 Geise GM, Lee HS, Miller DJ, et al. Water purification by membranes: The role of polymer science. J Polym Sci B Polym Phys, 2010, 48: 1685-1718

216 Long R, Kuang Z, Liu Z, et al. Ionic thermal up-diffusion in nanofluidic salinity-gradient energy harvesting. Natl Sci Rev, 2019, 6: 1266-1273

217 Wen L, Liu X, Yang N, et al. Photoelectric conversion behavior based on direct interfacial charge-transfer from porphyrin derivative to silicon nanowires. Appl Phys Lett, 2010, 97: 253111

218 Xiao K, Giusto P, Chen F, et al. Light-driven directional ion transport for enhanced osmotic energy harvesting. Natl Sci Rev, 2020, 7: nwaa231

219 Wen L, Tian Y, Guo Y, et al. Conversion of light to electricity by photoinduced reversible $\mathrm{pH}$ changes and biomimetic nanofluidic channels. Adv Funct Mater, 2013, 23: 2887-2893

220 Zhang Y, He Y, Tsutsui M, et al. Short channel effects on electrokinetic energy conversion in solid-state nanopores. Sci Rep, 2017, 7: 46661

221 Mansouri A, Vali A, Kostiuk LW. Electrokinetic power generation of non-newtonian fluids in a finite length microchannel. Microfluid Nanofluid, 2016, 20: 71

222 Xie Y, Wang X, Xue J, et al. Electric energy generation in single track-etched nanopores. Appl Phys Lett, 2008, 93: 163116

223 Osterle JF. Electrokinetic energy conversion. J Appl Mech, 1964, 31: 161-164

224 Osterle JF. A unified treatment of the thermodynamics of steadystate energy conversion. Appl sci Res, 1964, 12: 425-434

225 Burgreen D, Nakache FR. Efficiency of pumping and power generation in ultrafine electrokinetic systems. J Appl Mech, 1965, 32: 675-679

226 Morrison FA, Osterle JF. Electrokinetic energy conversion in ultrafine capillaries. J Chem Phys, 1965, 43: 2111-2115

227 Wang M, Hou Y, Yu L, et al. Anomalies of ionic/molecular transport in nano and sub-nano confinement. Nano Lett, 2020, 20: 6937-6946

228 Yang J, Lu F, Kostiuk LW, et al. Electrokinetic microchannel battery by means of electrokinetic and microfluidic phenomena. J Micromech Microeng, 2003, 13: 963-970

229 Chein R, Tsai K, Yeh L. Analysis of effect of electrolyte types on electrokinetic energy conversion in nanoscale capillaries. Electrophoresis, 2010, 31: 535-545

230 Zhang J, Zhan K, Wang S, et al. Soft interface design for electrokinetic energy conversion. Soft Matter, 2020, 16: 2915-2927

231 Wang $M$, Meng $H$, Wang $\mathrm{D}$, et al. Dynamic curvature nanochannel-based membrane with anomalous ionic transport behaviors and reversible rectification switch. Adv Mater, 2019, 31: 1805130

232 Wen L, Zhang X, Tian Y, et al. Quantum-confined superfluid: From nature to artificial. Sci China Mater, 2018, 61: 1027-1032

233 Zhang X, Antonietti M, Jiang L. Bioinformation transformation: From ionics to quantum ionics. Sci China Mater, 2020, 63: 167171

Acknowledgements This work was supported by the National Natural Science Foundation of China (22005162, 21675091, 21874078 and 22074072), China Postdoctoral Science Foundation (2019M652319), the Special Financial Aid to Post-doctor Research Fellow (2020T130330), Taishan Young Scholar Program of Shandong Province (tsqn20161027), the Major Science and Technology Innovation Project of Shandong Province (2018CXGC1407), the Key Research and Development Project of Shandong Province (2016GGX102028, 2016GGX102039 and 2017GGX20111), and the First Class Discipline Project of Shandong Province. 
Author contributions $\mathrm{MaH}$ and Sui $\mathrm{X}$ constructed the original writing framework; Ma $\mathrm{H}$ completed the first draft and Sui X completed the revision of the article. Wang S, Yu B, Shen Y, and Cong H provided many valuable suggestions during the writing.

Conflict of interest The authors declare that they have no conflict of interest.

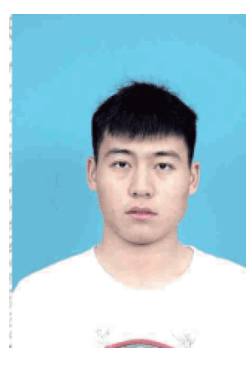

He Ma received his BSc degree in 2019 in materials science and engineering from Henan University of Technology. He is pursuing his MSc in the Department of Materials Engineering of Qingdao University and studying in Cong's lab. His research focuses on bioinspired nanochannels.

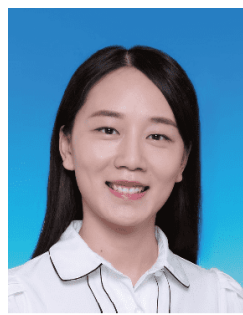

Xin Sui is a professor at the College of Materials Science and Engineering, Qingdao University. She received her $\mathrm{PhD}$ degree in materials physics and chemistry from the College of Chemstry, Beihang University. In 2016, she went to the New York University as a visiting scholar. She was appointed as a professor in 2018. Her scientific interests focus on polymer bioinspired nanochannel membranes for energy conversion and biosensors.

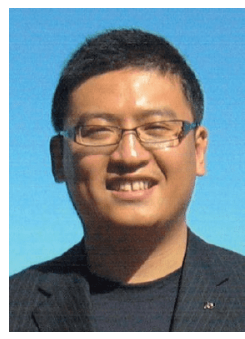

Hailin Cong received his $\mathrm{PhD}$ degree from Peking University in 2004 with Prof. Weixiao Cao. After completing a Postdoctoral Fellowship at the University of California, Davis, he joined Qingdao University in 2009 as a Distinguished Professor and Distinguished Young Scientist of Shandong Province. His current research interests lie in the synthesis and application of advanced micro-nano materials. He received The Natural Science Award from the Ministry of Education of China (2007). He has been a Member of the Editorial Board of Nanoscience \& Nanotechnology since 2008, the Vice Chair of the Editorial Committee of the China International Nanoscience and Technology Symposium since 2009, and a Member of the Editorial Board of Integrated Ferroelectrics since 2012.

\section{基于聚合物膜的仿生纳米通道}

马贺 ${ }^{1}$, 王松 ${ }^{1}$, 于冰 ${ }^{1,2}$, 随欣 ${ }^{1 *}$, 申有青 ${ }^{1,3}$, 丛海林 ${ }^{1,2^{*}}$

摘要 在生物体内, 细胞膜上的离子通道可以通过选择性地传输离 子参与生命活动. 受生物体内传输通道结构和功能的启发, 具有实 际应用价值的人工离子纳米通道备受关注. 基于高分子材料的仿 生纳米通道具有机械稳定性、离子输运性能优异和可设计性强等 特点. 本文主要介绍了基于聚合物的仿生纳米通道的制备及其在 环境响应性生物传感和能量转换方面的应用. 首先介绍了纳米通 道在离子传输调控和能量转换方面的基本特性. 之后, 我们讨论了 聚合物基纳米通道材料的制备方法, 并强调了它们相对于其他材 料的优势. 详细讨论了聚合物基仿生纳米通道在能量转换和环境 响应生物传感器中的实际应用. 最后, 总结了仿生纳米通道研究中 尚未解决的问题, 并对该领域的进一步发展方向进行了展望. 